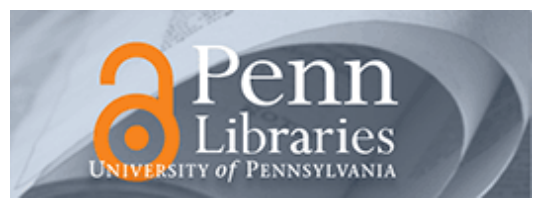

University of Pennsylvania ScholarlyCommons

September 2008

\title{
Dual-Beam Actuation of Piezoelectric AIN RF MEMS Switches Monolithically Integrated with AIN Contour-Mode Resonators
}

\author{
Rashed Mahameed \\ University of Pennsylvania \\ Nipun Sinha \\ University of Pennsylvania \\ Marcelo B. Pisani \\ University of Pennsylvania \\ Gianluca Piazza \\ University of Pennsylvania, piazza@seas.upenn.edu
}

Follow this and additional works at: https://repository.upenn.edu/ese_papers

\section{Recommended Citation}

Rashed Mahameed, Nipun Sinha, Marcelo B. Pisani, and Gianluca Piazza, "Dual-Beam Actuation of Piezoelectric AIN RF MEMS Switches Monolithically Integrated with AIN Contour-Mode Resonators", . September 2008.

Postprint version. Published in Journal of Micromechanics and Microengineering, Volume 18, Issue 10, Article No. 105011, October 2008.

This paper is posted at ScholarlyCommons. https://repository.upenn.edu/ese_papers/452

For more information, please contact repository@pobox.upenn.edu. 


\title{
Dual-Beam Actuation of Piezoelectric AIN RF MEMS Switches Monolithically Integrated with AIN Contour-Mode Resonators
}

\author{
Abstract \\ This work reports on piezoelectric Aluminum Nitride (AIN) based dual-beam RF MEMS switches that have \\ been monolithically integrated with AIN contour-mode resonators. The dual-beam switch design \\ presented in this paper intrinsically compensates for the residual stress in the deposited films, requires \\ low actuation voltage ( 5 to $20 \mathrm{~V}$ ), facilitates active pull-off to open the switch and exhibits fast switching \\ times ( 1 to $2 \mu \mathrm{s})$. This work also presents the combined response (cascaded $\mathrm{S}$ parameters) of a \\ resonator and a switch that were co-fabricated on the same substrate. The response shows that the \\ resonator can be effectively turned on and off by the switch. A post-CMOS compatible process was used \\ for the co-fabrication of both the switches and the resonators. The single-chip RF solution presented \\ herein constitutes an unprecedented step forward towards the realization of compact, low loss and \\ integrated multi-frequency RF front-ends.

\section{Keywords} \\ RF MEMS, Switches, Piezoelectric Devices, Piezoelectric Resonators, Aluminum Nitride

\section{Comments} \\ Postprint version. Published in Journal of Micromechanics and Microengineering, Volume 18, Issue 10, \\ Article No. 105011, October 2008.
}




\title{
Dual-Beam Actuation of Piezoelectric AIN RF MEMS Switches Monolithically Integrated with AIN Contour- Mode Resonators
}

\author{
Rashed Mahameed ${ }^{1}$, Nipun Sinha ${ }^{2}$, Marcelo B. Pisani ${ }^{1}$ and Gianluca Piazza ${ }^{1}$ \\ ${ }^{1}$ Electrical and Systems Engineering \\ ${ }^{2}$ Mechanical Engineering and Applied Mechanics \\ University of Pennsylvania, Philadelphia, Pennsylvania, USA
}

Email: mrashed@seas.upenn.edu , rmahameed@gmail.com, piazza@ seas.upenn.edu

\begin{abstract}
This work reports on piezoelectric Aluminum Nitride (AIN) based dual-beam RF MEMS switches that have been monolithically integrated with AlN contour-mode resonators. The dual-beam switch design presented in this paper intrinsically compensates for the residual stress in the deposited films, requires low actuation voltage (5 to $20 \mathrm{~V}$ ), facilitates active pull-off to open the switch and exhibits fast switching times (1 to $2 \mu \mathrm{s}$ ). This work also presents the combined response (cascaded $\mathrm{S}$ parameters) of a resonator and a switch that were co-fabricated on the same substrate. The response shows that the resonator can be effectively turned on and off by the switch. A post-CMOS compatible process was used for the co-fabrication of both the switches and the resonators. The single-chip RF solution presented herein constitutes an unprecedented step forward towards the realization of compact, low loss and integrated multi-frequency RF front-ends.
\end{abstract}

Keywords: RF MEMS, Switches, Piezoelectric Devices, Piezoelectric Resonators, Aluminum Nitride. 


\section{Introduction}

RF MEMS switches offer superior performances compared to FET and p-i-n diode switches. They are characterized by low power consumption, improved linearity, high isolation, and low insertion loss. The last decade has seen an increase in the efforts dedicated to the development of RF MEMS switches that can be employed in wireless communication systems [1].

Various actuation methods such as electrostatic [2-8], piezoelectric [9-12], electromagnetic [13-15] and thermoelastic [16-18] have been used in RF MEMS switches. Electromagnetic and thermoelastic actuation methods require high power consumption for actuation (few $\mathrm{mW}$ per device) and are incompatible with modern low power RF front-ends. Electrostatic actuation is the most commonly used actuation method. However, this mechanism requires high voltages ( $>50 \mathrm{~V} \mathrm{[1]}$ ) that necessitate the presence of a separate on-chip high voltage source or charge pump to operate the switch. Reduction in the actuation voltage can be achieved by decreasing the switch stiffness; however, the restoring force that is usually employed for opening the switch and the switching time, both decrease with the associated decrease in stiffness. This reduction in stiffness also affects the ultimate reliability of the switch.

The piezoelectric switch technology has the ability to meet the RF requirements of high isolation, low insertion loss, low power consumption and at the same time has the potential to overcome most of the drawbacks encountered in electrostatic switches. Lead Zirconate Titanate (PZT) is the most commonly used piezoelectric material for the development of RF MEMS switches. Few research groups [9-12] have already demonstrated PZT based switches that have the capability of low voltage actuation. PZT has very high piezoelectric coefficient values, but the presence of lead makes its fabrication process incompatible with CMOS electronics. AlN films have recently been introduced for RF applications and have demonstrated to be the preferred material for resonator applications [19-22]. AlN offers the ability of direct integration with CMOS over PZT. Furthermore, the monolithic integration of switches and recently introduced contour-mode resonator technology $[19,20]$ can significantly affect the way we design current RF front-ends by impacting their size, power efficiency and drastically reducing parasitics and off-state leakage. In addition, such integration will enable new RF architectures based on massive arrays of switched multi-frequency AlN contour-mode resonators [22].

In this paper, we present the first AlN based piezoelectric switch [23] that can be operated at relatively low voltages and has been fabricated by building upon the well established process for the making of AlN based contour mode resonators and filters [20, 24]. Furthermore, 
from a device perspective, the uniqueness of this work lies in the utilization of the dual-beam mechanism which uses two symmetric released beams for operating the switch. Both beams can be actuated simultaneously, thus giving: (i) immunity to residual stress and process-induced variation in the initial air-gap used to set the RF isolation level, (ii) low actuation voltage (halved), (iii) high contact forces (doubled for a given voltage), (iv) active pull-off to open the switch and (v) faster switching times (halved).

\section{Switch design and principle of operation}

The schematic view of the dual-beam AlN piezoelectric switch is shown in figure 1 . The device is made out of two actuated cantilever beams. The operating principle of each beam is based on the unimorph piezoelectric actuation design (figure 2)[25-27]. The routing of the bottom and middle metal layers (the layers that provide the actuation) is done in such a manner that two DC inputs can be used for actuating both beams simultaneously (see figure 1).

The layers that make up the unimorph piezoelectric actuator are: one active and one passive AlN layer, three layers of Platinum (Pt), a thin NiCr layer for electroplating and a thick layer of Gold (Au). The (bottom) active layer of AlN is sandwiched between two Pt electrodes (bottom and middle layers) that are used for applying the actuation potential across the piezoelectric layer. The top AlN layer is used to isolate the RF signal from the actuation electrodes. A third Pt layer (top layer) forms part of the switch contact and signal routing. A $\mathrm{NiCr}$ layer is used as adhesion layer for the Au seed layer. A thick layer of electroplated Au is used on top of the aforementioned AlN stack. The Au layer serves two purposes: firstly as a low resistance carrier for the RF signal, and secondly as a structural layer used for offsetting the neutral axis of the beam needed to produce the bending moment for the switch actuation.

In order to obtain a good RF performance in the proposed switch design, i.e. high isolation and low insertions loss (IL), a relatively large gap (in the open state) and low contact resistance (in the close state) are required. The contact resistance can be controlled and reduced either by increasing the contact forces (which is proportional to the actuation voltage and inversely proportional to the air-gap size) or by selecting contact material with low electric resistance. Another parameter, which can be utilized to improve the contact force, is the piezoelectric material properties. Using a piezoelectric material with high piezoelectric coefficients (e.g. PZT) can increase the actuator deflections, and consequently the contact force. However, as previously mentioned, other piezoelectric materials such as PZT are not compatible 
with CMOS and cannot be integrated with AlN contour-mode resonators. The switching time is an additional important parameter which should be taken into account in the switch design. This parameter is primarily restricted by air-gap size, actuation voltage, structure stiffness, structure resonance frequency and damping.

All aforementioned requirements (i.e. high isolation, low insertions loss and fast switching time with low actuation voltages) were taken into account in the design of the dualbeam switch. Accordingly, in order to demonstrate the first prototype of AlN-based switch, we set the minimum goals that can enable the development of integrated RF front-ends operating between $300 \mathrm{MHz}$ and $6 \mathrm{GHz}$ to be: good RF performance $(\sim 20 \mathrm{~dB}$ isolation and $\sim 0.5 \mathrm{~dB}$ of $\mathrm{IL}$ at $6 \mathrm{GHz})$ and fast switching time $(\sim 2 \mu \mathrm{s})$ with low actuation voltages $(<20 \mathrm{~V})$. It is important to note the relatively relaxed requirement for IL. In fact, in a fully integrated solution that uses contour-mode resonator technology and slightly higher impedance levels (200-300 $\Omega$ ) the IL requirements can be significantly reduced with respect to conventional RF front-ends.

Another important aspect that needs to be taken into account in the design of a MEMS switch is the effect of residual stresses. Residual stresses in MEMS devices are an unwanted effect that results from high temperature fabrication process steps. In microsystems, the residual stresses do not only affect the structural reliability, but also affect the performance of the system $[28,29]$. Due to the small size of the MEMS switches, the deflection induced by residual stresses strongly affects the switch performance; either the required applied voltage to close the switch increases or the switch gap can be spontaneously closed after release. Therefore, it is essential to eliminate this effect in MEMS switches. The dual-beam design was introduced primarily because of the need to fabricate switches immune to residual stresses. In the next sections, details are presented on the use of two symmetric released cantilever beams to reduce the effect of residual stresses and the fundamental mechanical considerations that needed to be taken into account to design the switch.

\subsection{Residual stresses compensation}

Residual stress gradient in as-deposited AIN films is very large and produces significant deflections in cantilever beams. Figure 3 shows a profile image of an as-deposited and released AlN cantilever beam obtained using a Zygo optical profilometer. The beam dimensions are: length $L=300 \mu \mathrm{m}$, width $w=100 \mu \mathrm{m}$ and thickness $t=2 \mu \mathrm{m}$. Due to the stress gradient across the thickness of the AlN film, the beam bends up. The beam profile along the beam length is also 
presented in figure 3 and shows that the induced edge deflection due to the stress gradient is $\delta_{s} \approx 22 \mu \mathrm{m}$. Such deflections will strongly affect the switch performance and make it unusable. Therefore, the first step towards stress reduction focused on the tuning of the deposition parameters of the AlN films. To reduce the stress gradient, the deposition process of the AIN films in a Tegal PVD system was modified and a heat treatment step was included. Stress gradient, with and without heat treatment, for different cantilever beams is measured and presented in figure 4a. As shown in this figure, the use of heat treatment during the AlN deposition reduces the stress gradient by six-folds from $\sim 600 \mathrm{MPa} / \mu \mathrm{m}$ to $\sim 100 \mathrm{MPa} / \mu \mathrm{m}$. Figure $4 \mathrm{~b}$ and $4 \mathrm{c}$ present the profile image of AlN beams with and without heat treatment. For typical AlN cantilever beams with $w=100 \mu m, t=2 \mu m$ and different lengths (i.e. $L=100-500 \mu m$ ), the edge deflection after heat treatment is reduced from $\delta_{s} \approx 10-150 \mu m$ to $\delta_{s} \approx 0.5-10 \mu \mathrm{m}$. Although acting on the deposition parameters could significantly reduce the stress gradient in the film, the residual level of stress still has a deleteriously effect on the switch operation, especially if air gaps smaller than $500 \mathrm{~nm}$ are used.

In addition to the residual stress-gradient, thermal stress is another source of residual stress in surface micromachining process. Thermal stress, which manifests itself as in-plane stress, is caused by differences in the thermal expansion coefficients of the deposited material and the substrate, and due to the difference between the fabrication and room temperatures [30]. Although the in-plane stress in AlN films can be accurately tuned to be within $\pm 100 \mathrm{MPa}$ by controlling the gas flow rates, the presence of a stack of films in the switch structure can still experience undesired deflection due to in-plane stress in the different films. Accordingly, the combination of the stress gradient (mainly from the AlN film) and the in-plane stress in the layer stack is very complicated and hard to control just by acting on the stress in each layer.

To further reduce the deleterious effect of stress (i.e. stress-gradient and in-plane stress) on the switch operation, a dual-beam mechanism is used in this work. The switch consists of two symmetric released cantilever beams. As shown in figure 5, the initial gap $(g)$ is nearly unaffected by the deflection $\left(\delta_{s}\right)$ due to residual stresses. Previous work [31] has suggested a folded beam mechanism for canceling the curling of the piezoelectric AlN actuator beam due to residual stress [31]. Although the proposed compensation mechanism is quite effective, it does not offer an optimal solution for a switch for which fast switching times and high forces are required and which cannot be achieved with relatively large structures. In this work, by 
separating the two beams, smaller devices can be fabricated, which assure that large forces and fast switching can simultaneously be attained.

Furthermore, difference in the thermal expansion coefficients of the materials used in the making of the AlN actuator (Au and AlN primarily) can cause changes in the isolation gap when temperature variations are experienced during switch operation. As it will be experimentally proven, the dual beam design is also insensitive to this.

\subsection{Mechanical analysis and simulations}

The switch performance requirements described in terms of IL, isolation and switching time translate into equivalent mechanical parameter that need to be taken into account in the design phase. More specifically, contact force, gap size and area, resonance frequency and actuation voltage need to be chosen in order to meet the desired specifications. In this section we present the static and dynamic mechanical analysis of the AlN dual-beam micromechanical switch.

The simulations and calculations in this section relate to a unimorph cantilever beam formed by stacked layers of Pt, AlN, Pt, AlN and Au (as shown in figure 6a). The material properties of the layers that are used in this work are summarized in Table 1. To simulate the contact forces in the switch, the edge deflection of a piezoelectric unimorph actuator is analyzed using COMSOL ${ }^{\circledR}$ FEM code. Figure $6 \mathrm{~b}$ shows the simulated edge deflection $(\delta$ ) of the cantilever beam as a function of the Au layer thickness. In this case, the beam has length, $L=200 \mu \mathrm{m}$, width, $w=200 \mu \mathrm{m}$, the AlN thickness is $t_{\text {AlN }}=1 \mu \mathrm{m}$, the Pt thickness is $t_{P t}=200 \mathrm{~nm}$ and the applied voltage for actuation is $V=25$ volt . The chosen thicknesses of the AlN and Pt layers in the switch design (i.e. $t_{A l N}=1 \mu \mathrm{m}$ and $t_{P t}=200 \mathrm{~nm}$ ) are restricted by the design requirements of the co-fabricated contour-mode resonators. Some variations in the relative thicknesses of the two AlN layers are possible, but were not considered for ease of fabrication and integration with the contour-mode resonators in this first demonstration.

When the switch gap ( $g$ ) is smaller than $\delta$, then an external force develops on the beam edge (see figure 7a). This force can be determined by

$$
F=\frac{3 E_{e q} I}{L^{3}}(\delta-g)
$$


where $E_{e q}$ is the equivalent Young's modulus for the stacked layers and $I$ is their moment of inertia $\left(I=w t^{3} / 12\right)$. For the specific beam under study and a gap of $g=200 \mathrm{~nm}$, the contact force that develops between the two beams ranges between 0 and $32 \mu \mathrm{N}$ ( figure $7 \mathrm{~b}$ ) at $V=25$ volt . As shown in figure $7 \mathrm{~b}$ the contact force reaches a maximum for a specific $\mathrm{Au}$ thickness. This can be intuitively understood, since, when the Au layer is thin, the beam deflects more and the beam stiffness $\left(k=3 E_{e q} I / L^{3}\right)$ is low, whereas when the Au layer is thick, the beam deflection is small and the beam stiffness is high. Therefore, a specific Au thickness for which the contact force is at its maximum must exist. As shown in this figure, the location of the $\mathrm{Au}$ optimum thickness is also affected by the actuation voltage, and higher forces can be attained with an increase in the actuation voltage.

In order to estimate the switching time of the switch, the piezoelectric unimorph actuator was simplified to a second-order system with mass, $m$, spring constant, $k$, and damping coefficient, $c$ (see figure $8 \mathrm{a}$ ). The external force, $F_{p}$, driving the simple spring, mass, damper system is equivalent to the piezoelectric force generated by a unimorph actuator and it is given by [32]

$$
\begin{aligned}
& F_{p}=d_{31} V \frac{3 w t_{a} E_{a}}{4 L} \frac{A B(B+1)}{A B+1} \\
& A=E_{p} / E_{a}, B=t_{p} / t_{a}
\end{aligned}
$$

where $d_{31}$ is the piezoelectric coefficient, $V$ is the applied voltage across the piezoelectric layer. $t_{a}$ is the thickness of the active AlN layer (i.e. bottom layer), $t_{p}$ is the thickness of the passive layers (i.e. Pt-AlN-Au), $E_{p}$ and $E_{a}$ are the Young's modulus of the passive layers and the active AlN layer, respectively.

For small displacements, the linear motion, $x$, as a function of time, $t$, is described by a linear second-order differential equation

$$
m \ddot{x}(t)+c \dot{x}(t)+k x(t)=F_{p}
$$

The analytical solution for (3) is

$$
x(t)=\frac{F_{p}}{k}\left[1-\frac{1}{\sqrt{1-\zeta^{2}}} \cdot e^{-\zeta \omega_{n} t} \cos \left(\omega_{d} t-\phi\right)\right]
$$


where $\zeta$ is the damping ratio, $\omega_{n}=2 \pi f_{r}$ is the natural frequency of the system, $\omega_{d}=\omega_{n} \sqrt{1-\zeta^{2}}$ is the damped natural frequency and $\phi=\tan ^{-1}\left(\zeta / \sqrt{1-\zeta^{2}}\right)$.

For an AlN unimorph beam with $L \times w=200 \mu m \times 200 \mu m, t_{A l N}=1 \mu m, t_{P t}=200 \mathrm{~nm}$, $V=22$ volt,$f_{r}=60 \mathrm{kHz}$ (i.e. Au thickness $t_{A u}=2.3 \mu \mathrm{m}$ ) and the same material properties presented in Table 1, the dynamic response of the approximated second-order system is presented in figure $8 \mathrm{~b}$. This figure shows that the required time to close the switch, or better, the needed

time for each beam edge to travel half the gap $\left(x\left(t^{*}\right)=g / 2=100 \mathrm{~nm}\right)$ is $t^{*}=1.9-2.2 \mu \mathrm{s}$. The experimental results presented in section 4 , for the same switch dimensions and actuation voltage, are in agreement with these predictions and confirm the validity of this simple $2^{\text {nd }}$ order model. It is important to note that the choice of a small gap significantly reduces the switching time and potentially limit bouncing phenomena occurring at closing.

As previously mentioned, the actuation electrodes for both beams are connected in such a way that the actuation pads can be used to drive the two beams simultaneously. In this fashion, significant advantages over other MEMS switch implementations can be attained. In fact, it should be clear from the previous analysis that the actuation voltage for closing the gap is reduced, the contact force is increased (double at a given voltage), and the switching time is decreased (half at a given voltage).

From this preliminary mechanical analysis, it is shown that the dual-beam design can provide good contact forces and fast switching $(\sim 2 \mu \mathrm{s})$ with relatively low actuation voltages $(<20 \mathrm{~V})$. According to these analyses a set of piezoelectric beams with dimensions varying between $200 \mu m \times 200 \mu m$ and $300 \mu m \times 100 \mu m$ were employed for the demonstration of the first AlN switch prototype. An air gap of $200 \mathrm{~nm}$ was selected as a compromise within high forces, fast actuation and acceptable isolation $(>20 \mathrm{~dB}$ at $6 \mathrm{GHz})$.

\section{Fabrication process}

A seven-mask potentially post-CMOS compatible process is used for the co-fabrication of AlN based switches and contour-mode resonators (figure 9). The process builds upon some of the previously developed microfabrication steps used for the demonstration of AlN contour-mode resonators [19-22]. As shown in figure 9: $1 \mu \mathrm{m}$ of $\mathrm{AlN}$ is deposited on top of a $300 \mathrm{~nm}$ insulating layer of low stress nitride (LSN) and $200 \mathrm{~nm}$ of Pt is patterned by lift-off. On 
this first layer of AlN, a second layer of AlN $(1 \mu \mathrm{m})$ is deposited on top of a second layer of Pt $(200 \mathrm{~nm})$. Opening to the bottom and middle electrodes are made by wet-etching of AlN using AZ400k ${ }^{\circledR}$ (a $\mathrm{KOH}$ based developer) at $70^{\circ} \mathrm{C}$. This step shows an improvement in terms of sidewall angle control and reduced surface roughness over [16, 20, 21] in defining the via opening. The AIN is patterned by a $\mathrm{Cl}_{2}$ based dry etch process using $\mathrm{SiO}_{2}$ as hard mask. The top Pt (200 $\mathrm{nm}$ ) layer is deposited and patterned by lift-off to form part of the contact and provide access to the bottom and middle Pt layers. At this point, the required steps to fabricate the contour-mode resonators are completed (see figure 9e).

To conclude the fabrication process of the dual-beam switch, an amorphous silicon layer is evaporated and patterned by lift-off. This layer is used to form the sacrificial layer to create the air-gap. The silicon layer covers the sidewall of the trench to avoid sticking between the two beams that comprise the switch (figure 9f). As mentioned before, the air-gap size strongly affects the RF performance and the switching time of the switch. Therefore, in this first switch prototype, a $200 \mathrm{~nm}$ film of evaporated silicon is used to create the air-gap. A gold/nickel-chrome layer is evaporated and used as seed layer for the electroplating of a thick gold layer. To achieve good sidewall coverage in the trench, the wafer was tilted during the gold evaporation. A thick photoresist (SPR-220) is employed as a mold for the electroplated layer. After wet etch of the seed layer, the sacrificial layer along with the structure are simultaneously dry-released using $\mathrm{XeF}_{2}$. Dry release is used to eliminate stiction problems that would have otherwise been encountered with wet release techniques. Figure 10 shows a Scanning Electron Microscopy (SEM) of one of the microfabricated switches with a close up view of the air-gap. As shown in this figure, the switch has a gold-platinum contact and a nano air-gap of approximately $200 \mathrm{~nm}$.

\section{Experimental results}

The experimental characterization of the switch focused on the measurement of the actuator resonance frequency and displacement, and the device switching time, on resistance, and preliminary RF response. The following sections summarize all these characterizations.

\subsection{Mechanical characterization of switch}

The resonant frequency of the AlN piezoelectric actuator was measured using Agilent 4294A Precision Impedance Analyzer. The measurement of a $200 \mu m \times 200 \mu m$ actuator under 
vacuum ( $p=6.6 \times 10^{-6}$ Torr ) shows that the first resonant frequency (bending) of this piezoelectric actuator occurs at $f_{r}=47.66 \mathrm{kHz}$. A comparison between the measured resonant frequencies for several actuator dimensions is presented in figure 11. For other test structures with the same dimensions a resonant frequency of $f_{r}=48.7-53.12 \mathrm{kHz}$ was reported. The small difference between the experimental results and the simulations results from an alteration of the effective boundary conditions after the isotropic release of the structure in $\mathrm{XeF}_{2}$. The anchors of the tested structures are partly released; this result in a corresponding increase of the effective length of the beam and a non-ideal clamped-free boundary condition as was instead considered in the simulations (see figure 12). This issue can be reduced by redesigning the release trench for the device in such a way that the trench width starts small close to the anchor and gradually increases along the beam length. In this manner a reduced amount of silicon will be removed in proximity of the anchor. To experimentally verify the effect of the clamped-free boundary condition on the resonant frequency of the actuators, the resonance frequency of $200 \mu m \times 100 \mu m$ beams with different Au anchor sizes were measured and are presented in figure 13. From these data, we can conclude that a stiffening of the anchoring region (Au anchor size changed from $50 \mu m \times 200 \mu m$ to $150 \mu \mathrm{m} \times 450 \mu \mathrm{m})$ is associated with an increase in the resonant frequency of the beam.

Edge deflection measurements of the actuator were performed using a Zygo optical profilometer. The edge deflection for a $300 \mu m \times 100 \mu m$ unimorph actuator as function of the applied voltage was measured. Using the formula for the edge deflection of a unimorph piezoelectric actuator reported in [32], the piezoelectric coefficient of the AlN was extracted, $d_{31}=-1.83 \times 10^{-12} \mathrm{~m} / \mathrm{V}$, and shows very good agreement with the reported value, $d_{31}=-2 \times 10^{-12} \mathrm{~m} / V$ [33]. The good agreement is also confirmed by FEM simulations, which show that the AlN thin film has good piezoelectric properties and bulk-like mechanical characteristics. Also, this agreement permits us to extract the value of contact forces which should be in line with the design values. Furthermore, the ability to maintain a perfectly linear response for both positive and negative voltages is a unique advantage of AlN over ferroelectrics, such as PZT, for which domain inversion can occur and limited symmetry in the displacement-voltage curve can be achieved. Furthermore, the crystal quality of the AlN film was verified by X-ray diffraction measurements. The measurements show good c-axis orientation (001) $\left(36.15^{\circ} \pm 0.05^{\circ}\right)$, with a full width half maximum (FWHM) of $2^{\circ}$. 
In order to experimentally determine the switching time of the AlN switch, a square-wave at $40 \mathrm{~Hz}$ was used to turn the switch on and off, while the change in a DC signal applied across the RF line (i.e. across RF IN and RF OUT of figure 10) was monitored to measure the occurrence of contact. The switching time is defined as the time for the output signal (i.e. RF OUT, in figure 10) to rise from 10 to $90 \%$ of the maximum output signal level in the on state. As shown in figure 14 , a switching time of $\sim 1.6 \mu \mathrm{s}$ was recorded for the $200 \mu \mathrm{m} \times 200 \mu \mathrm{m}$ switch. Repeated tests on other switches and at different actuation frequencies and voltages confirmed that the switching time lies between 1 and $2 \mu \mathrm{s}$. These values are very close to $1.9-2.2 \mu \mathrm{s}$, which was extracted from the solution of the equivalent second-order system in section 2.

\subsection{Electrical characterization of switch}

The on-resistance $\left(R_{o n}\right)$ measurements of the dual beam switch were performed using a DC power supply (for actuation) and a multimeter for measuring the resistance across the RF line (i.e. across RF IN and RF OUT of figure 10). DC resistance measurements of the switches show that the contact resistance decreases with the applied voltage, proving that higher forces produce lower $R_{o n}$. As previously described, the dual-beam actuation scheme takes advantage of this concept and uses two actuators to double the force per unit applied voltage. To further validate this, the change in on-resistance with the applied voltage when either one beam or both beams are actuated, was measured (figure 15). The plot in figure 15 shows that $6.3 \mathrm{~V}$ are needed to establish contact for $200 \mu m \times 200 \mu m$ switch (vs. $12 \mathrm{~V}$ for the single beam) when both beams are actuated and the on-resistance decreases to $\sim 5.4 \Omega$ at $40 \mathrm{~V}$ (vs. $8.4 \Omega$ for a single beam at the same voltage). This example clearly verifies the advantage of the dual-beam actuation mechanism. It should also be pointed out that some other switches, with larger contact area exhibited even lower on-resistance $\left(R_{o n}=3 \Omega\right.$ ) for the same applied voltage. It is important to note that, as shown in figure 15 , at a certain voltage $(\sim 40 \mathrm{~V})$ the on-resistance reaches a steady-state value and it is no longer affected by the applied forces. This is most probably due to either the type of metal used (resistivity of $\mathrm{Pt}$ is relatively higher than other metals such $\mathrm{Au}$ and $\mathrm{Cu}$ ) or a sliding effect in the mechanical contact. Instead of producing an actual contact force, the beams are actually sliding against each other. This can be verified by the fact that the switch has not shown any improvement in the $R_{\text {on }}$ even after applying high voltages ( $>40 \mathrm{~V}$ ) or subjecting it to external forces that were manually applied by means of micromanipulated probes. Therefore, the use of different contact materials with low resistivity, such as rhenium and gold-palladium alloys, might 
reduce the $R_{\text {on }}$ of the switch. In addition to the contact material, roughness of the contact surface and contamination around the contact area are considered to be other mechanisms, which can strongly affect the contact resistance of the switch. These mechanisms can be mitigated by using other deposition techniques for the sacrificial layer or by improving the cleanliness of the contact area by means of packaging, flowing nitrogen or heating up the switch to remove any organic layer in the contact area [1].

Preliminary RF measurements were performed in order to verify the RF response of this first AlN switch prototype. Figure 16 presents the isolation and the insertion loss of a $200 \mu m \times 200 \mu m$ dual-beam AlN switch. In this switch, isolation $>26 \mathrm{~dB}$ and low Return Loss (RL) $<0.75 \mathrm{~dB}$ at $2 \mathrm{GHz}$ were obtained. The current isolation response is limited by a combination of the switch contact size, gap dimensions and parasitics. The equivalent off-state capacitance extracted from the $S_{21}$ is $42 \mathrm{fF}$ at $2 \mathrm{GHz}$ and it is about 8 times the capacitance of just the switch gap. Insertion Loss (IL) $<0.67 \mathrm{~dB}$ and $\mathrm{RL}>34 \mathrm{~dB}$ were recorded at $2 \mathrm{GHz}$ for this same switch. The higher than expected IL value is likely due to substrate parasitics. In fact, as shown in Figure 16, the switch response is compared to a through-line on the same substrate. A better design and selection of the electrical layout and signal routing can reduce the effects of parasitics. The additional losses are also likely to be due to an unwanted coupling between RF and DC signals, which can be warranted by improved care in the layout of the actuation signal.

We also characterized the switch response over temperature. Temperature is varied between $\sim 300 \mathrm{~K}$ and $350 \mathrm{~K}$ and the corresponding capacitance (off-state) and on-resistance (onstate) response is recorded. Figure 17 presents these data and shows that the normalized capacitance (with the capacitance at $300 \mathrm{~K}$, i.e. $C / C_{300 K}$ ) and the normalized on-resistance (with the resistance at $300 \mathrm{~K}$, i.e. $R / R_{300 K}$ ) of the switch change by less than $\pm 7 \%$ over the entire temperature range. Accordingly, we have proven that the response of the dual-beam switch is stable and not affected by the change in the ambient temperature thanks to the symmetric design of the two released beams.

The same switch was fabricated in conjunction with several AlN contour-mode resonators on the same substrate (as shown in figure 18). Figure 19 shows the combined response (cascaded S-parameters) of a $224 \mathrm{MHz}$ resonator and the switch. The overlap between the resonator response with and without the switch shows that the introduction of the switch does not significantly alter the resonator performance. The same figure of merit $\left(k_{t}^{2}=2 \%, Q=2000\right)$ of the resonator is preserved and the small switch resistance that appears in series with the resonator 
does not significantly impact the overall resistance of the combined system. Furthermore, the switch effectively turns off the resonator by lowering its transmission response by at least $39.5 \mathrm{~dB}$. For example, this switch could effectively turn on and off a bank of different frequency resonators placed in the same Pierce oscillator circuit as was demonstrated in [34].

\section{Conclusions}

In this work the design, fabrication and experimental testing of the first piezoelectric AlN dual-beam switch monolithically integrated with AlN contour mode resonators has been demonstrated. The dual-beam switch design has demonstrated immunity to residual stresses, exhibits fast switching time ( 1 to $2 \mu \mathrm{s}$ ), requires low actuation voltage ( 5 to $20 \mathrm{~V}$ ), facilitates active pull-off to open the switch and its isolation is insensitive to high ambient temperature. The RF performance of the first prototype dual-beam switch has been evaluated and shows good isolation $(>26 \mathrm{~dB})$ and IL $(<0.67 \mathrm{~dB})$ at $2 \mathrm{GHz}$. Ongoing research is focusing on long-term reliability testing and optimization of the switch in order to reduce IL and actuation voltage. Demonstration of integrated arrays of switches and AIN filters is also in progress.

\section{Acknowledgment}

This work was supported by the DARPA ASP Project. The authors will like to acknowledge the help provided by Chengjie Zuo and Carlos R. Perez at the Penn Micro and Nano Systems (PMaNS) laboratory, Philip Stephanou and Justin Black at Harmonic Devices Inc. and the staff at the Penn Wolf Nanofabrication Facility. 


\section{Tables}

\begin{tabular}{|c|c|c|c|c|}
\hline Material & $\boldsymbol{\rho}\left[\mathbf{k g} / \mathbf{m}^{\mathbf{3}}\right]$ & $\mathbf{E}[\mathbf{G p a}]$ & $\mathbf{v}$ & $\mathbf{d}_{\mathbf{3 1}}[\mathbf{m} / \mathbf{V}]$ \\
\hline $\mathrm{AlN}$ & 3,200 & Stiffness matrix $[35,36]$ & 0.24 & $-2 \times 10^{-12}[33]$ \\
\hline $\mathrm{Pt}$ & 27,000 & 168 & 0.3 & - \\
\hline $\mathrm{Au}$ & 19,300 & 70 & 0.44 & - \\
\hline
\end{tabular}

Table 1 - Typical material properties of AlN, Pt and Au. 


\section{Figures captions}

Figure 1: $\quad 3 D$ schematic view of the dual-beam AlN RF MEMS switch. This mock up view illustrates how both arms of the switch can be actuated at the same time.

Figure 2: $2 \mathrm{D}$ schematic view of the dual-beam switch showing the operating principle of the switch: the bottom layer of AlN is used for actuation; by reversing the polarity of the applied voltage (done by on-chip electrode routing) the switch can either be opened or closed.

Figure 3: $\quad$ Beam profile along the length of a released AlN cantilever beam (beam image in the top left corner). The beam dimensions are: length $L=300 \mu m$, width $w=100 \mu m$ and thickness $t=2 \mu m$.

Figure 4: (a) Calculated stress gradient for different cantilever beams without heat treatment (blue squares marks) and with heat treatment (red circular marks). The lower part of the figure shows interferometric images of the beams without (b) and with (c) heat treatment.

Figure 5: Schematic representation of stress gradient compensation enabled by the dual beam mechanism. (a) shows an unreleased switch with air-gap, $g$; (b) represents what would happen if just one beam is released and (c) shows what occurs when both beams are released. In this last case the gap size is preserved. The same is valid for when the switch structure is exposed to temperature variations.

Figure 6: (a) Schematic view of piezoelectric unimorph actuator. (b) Beam edge deflection as function of $\mathrm{Au}$ thickness. The beam has a length, $L=200 \mu \mathrm{m}$, width, $w=200 \mu \mathrm{m}$, the AlN thickness is $t_{A l N}=1 \mu \mathrm{m}$, the Pt thickness is $t_{P t}=200 \mathrm{~nm}$ and the applied voltage for actuation is $V=25$ volt .

Figure 7: (a) Side view of piezoelectric unimorph actuator schematically illustrating the method used to calculate contact force. (b) The simulated contact force for the following beam geometry $L=200 \mu \mathrm{m}, w=200 \mu \mathrm{m}, t_{A l N}=1 \mu \mathrm{m}, t_{P t}=200 \mathrm{~nm}$, $g=200 \mathrm{~nm}$ as a function of Au thickness and different values of applied voltage.

Figure 8: $\quad$ (a) Schematic representation of the second-order system used to model the switch dynamic response. Here, $k$ represents the beam stiffness, $c$ the coefficient of 
damping in the system, $m$ mass of the system and $F_{p}$ the equivalent driving force due to piezoelectric actuation of the beam. (b) Dynamic response of the equivalent second-order system for different values of quality factor (Q). A beam dimension of $L \times w=200 \mu m \times 200 \mu m, t_{A l N}=1 \mu m, t_{P t}=200 \mathrm{~nm}$ with $2.3 \mu \mathrm{m}$ Au thickness was assumed. An actuation voltage of $V=22$ volt was used.

Figure 9: $\quad$ Process flow of the dual-beam switch fabricated with contour-mode resonators. (a) First AlN layer on top of Pt and LSN. (b) Second AlN layer on top of middle Pt. (c) Opening of via to bottom and middle Pt. (d) AlN Etch. (e) Top Pt deposition. (f) Si sacrificial layer. (g) Gold Electroplating. (h) $\mathrm{XeF}_{2}$ Release of structures.

Figure 10: $\quad$ SEM of the fabricated AIN switch with a zoomed in view of the nano-gap and $\mathrm{Au} / \mathrm{Pt}$ contact region. The nano-gap is realized by using evaporated amorphous silicon as sacrificial layer. The sacrificial layer is removed by using $\mathrm{XeF}_{2}$ vapor phase release. The nano-gap definition is key in enabling switches with large forces and good RF isolation.

Figure 11: Comparison between measured, simulated and analytically calculated resonant frequencies of several $200 \mu m \times 200 \mu m$ and $300 \mu m \times 100 \mu m$ actuators with $\mathrm{Au}$ thickness $t_{A u}=2.3 \mu \mathrm{m}$. Simulation results for different $\mathrm{Au}$ thicknesses are also provided to show how Au thickness can be employed to fine tune the device resonant frequency.

Figure 12: $\quad$ SEM of a fabricated piezoelectric actuator. The bright color around the trench demonstrates the isotropic etch of silicon around the structures by $\mathrm{XeF}_{2}$. To reduce the effect of the unwanted released area (underneath the anchor) on the structure stiffness, the trench width can be reduced in the area close to the anchor. In this case a thick and wide Au layer was used to stiffen the clamping location.

Figure 13: Measured resonant frequency of several $200 \mu m \times 100 \mu m$ for different $\mathrm{Au}$ anchor size. The inset represents the beam and anchor geometry. The beam size is fixed ( $200 \mu m \times 100 \mu m$ ) whereas width and length of the anchor are changed. In these test structures the resonant frequency is also affected strongly by the increasing in the effective beams length after the isotropic release of the structure in $\mathrm{XeF}_{2}$. 
Figure 14: $\quad$ Response of the $200 \mu m \times 200 \mu m$ switch to a square waveform signal $( \pm 22 \mathrm{~V})$ at $40 \mathrm{~Hz}$. The square waveform was used to turn the switch on and off, while the change in a DC signal applied across the RF line was monitored to measure the occurrence of contact.

Figure 15: $\quad$ DC on resistance $\left(R_{o n}\right)$ measurements of a switch $(200 \mu m \times 200 \mu m)$ for which single and both beams were actuated. The dual beam actuation shows lower resistance for a given voltage.

Figure 16: Measurement of isolation and insertion loss (IL) for a $200 \mu m \times 200 \mu m$ dualbeam AlN switch from $10 \mathrm{MHz}$ to $10 \mathrm{GHz}$. Switch IL is compared to the loss in a through line of comparable length.

Figure 17: Normalized capacitance (at $2 \mathrm{GHz}$ ) and normalized on-resistance of $300 \mu m \times 100 \mu m$ switch at different ambient temperature.

Figure 18: SEM showing dual-beam actuated AIN switches co-fabricated with AIN resonators on the same silicon substrate.

Figure 19: $\quad \mathrm{S}_{21}$ plot (cascaded S-parameters) of a resonator monolithically integrated with the AlN switch presented in this work. The response of a resonator with the switch in both on and off states is compared to the response of the resonator without the switch. No significant changes in the resonator response were recorded. The resonator is effectively turned off by the switch. 


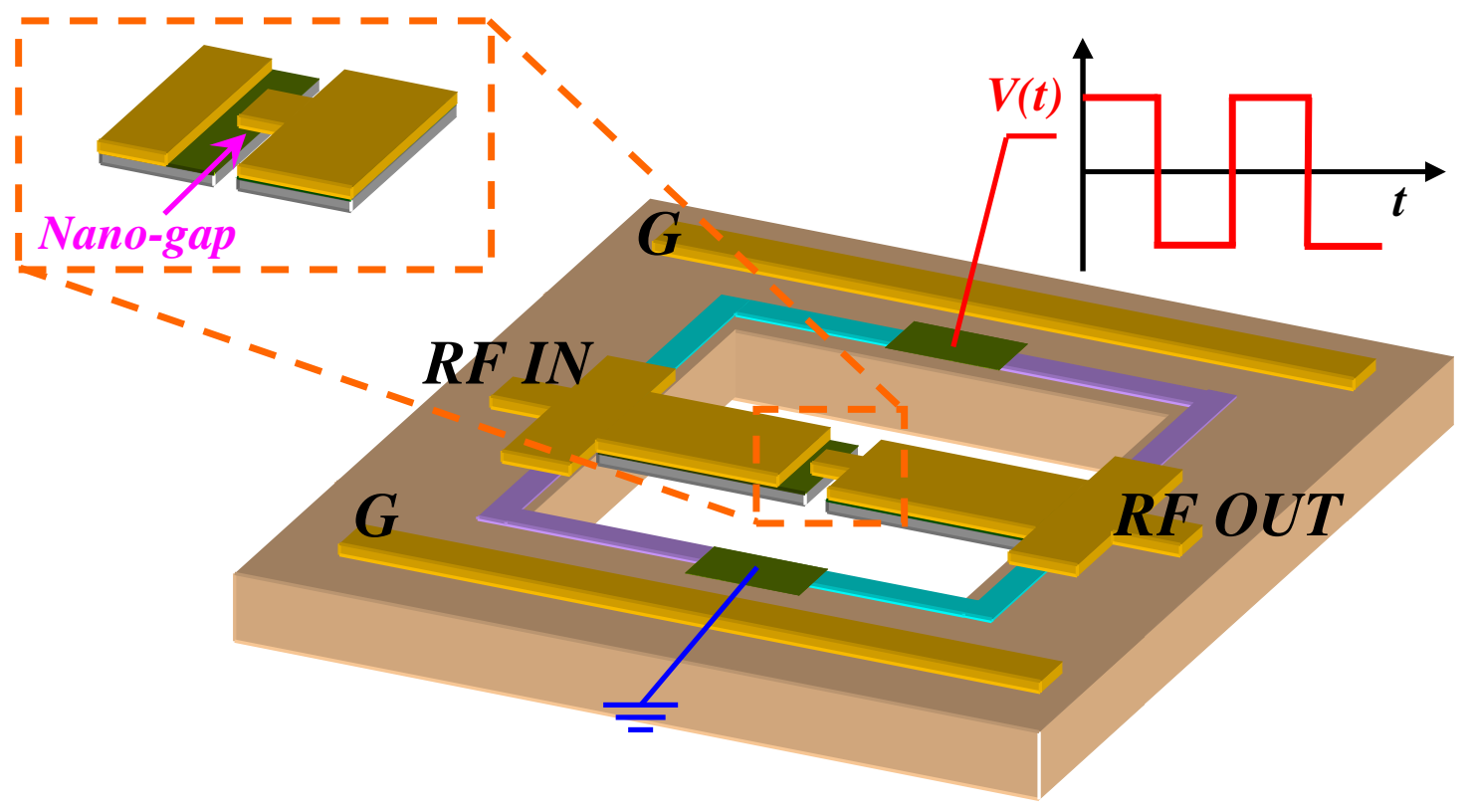

Figure 1. 3D schematic view of the dual-beam AlN RF MEMS switch. This mock up view illustrates how both arms of the switch can be actuated at the same time. 

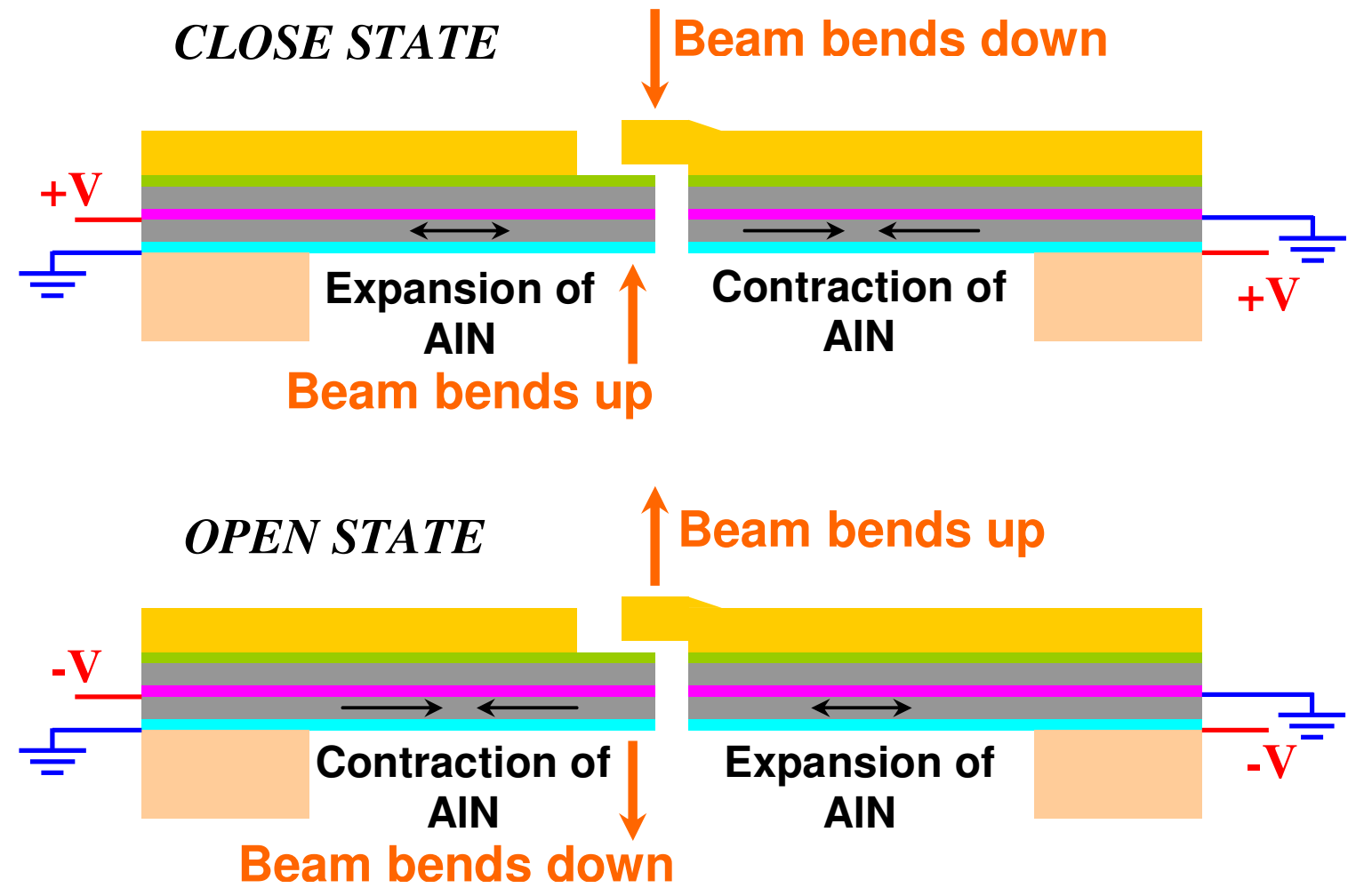

Figure 2. 2D schematic view of the dual-beam switch showing the operating principle of the switch: the bottom layer of AlN is used for actuation; by reversing the polarity of the applied voltage (done by on-chip electrode routing) the switch can either be opened or closed. 


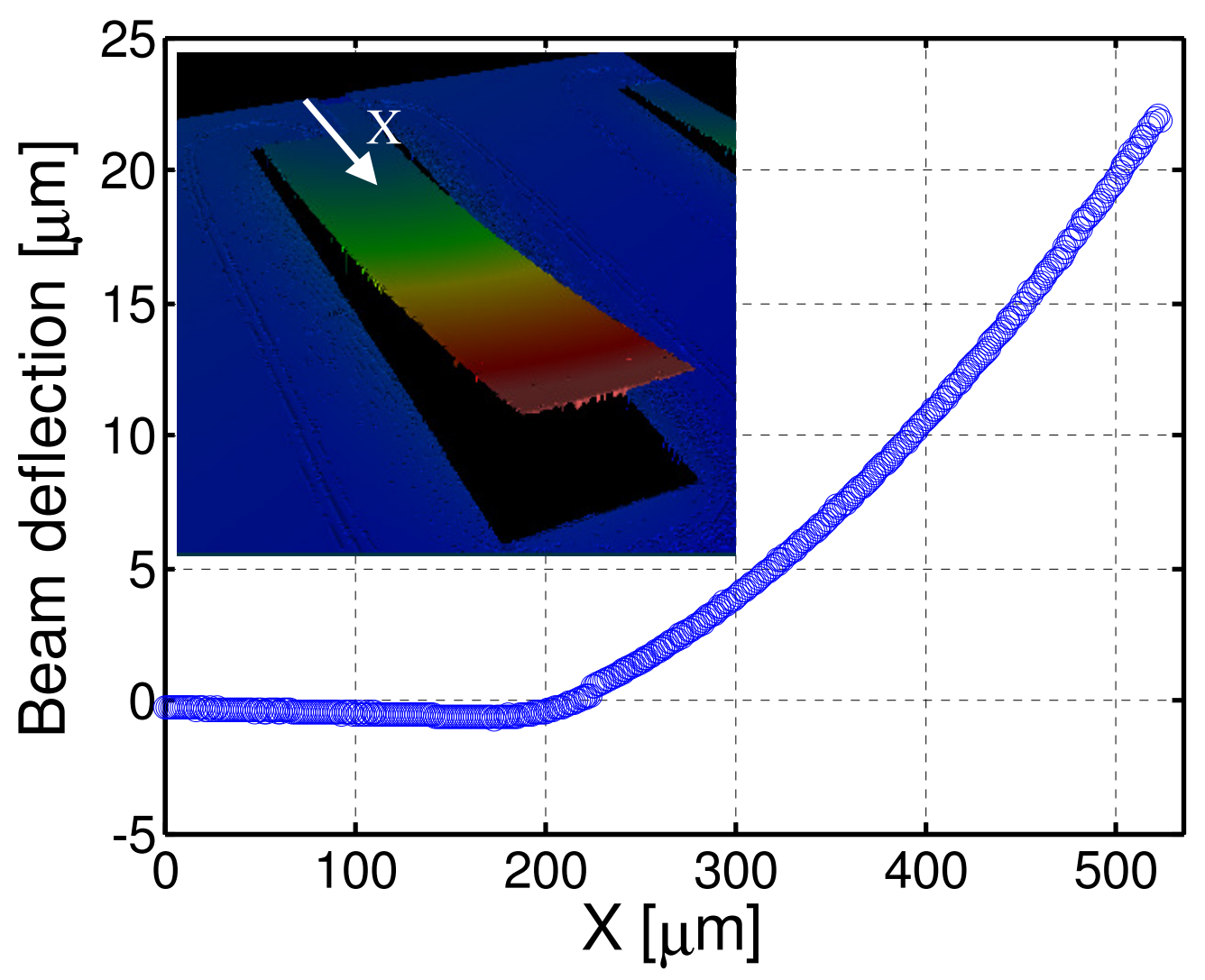

Figure 3. Beam profile along the length of a released AlN cantilever beam (beam image in the top left corner). The beam dimensions are: length $L=300 \mu m$, width $w=100 \mu m$ and thickness $t=2 \mu \mathrm{m}$. 


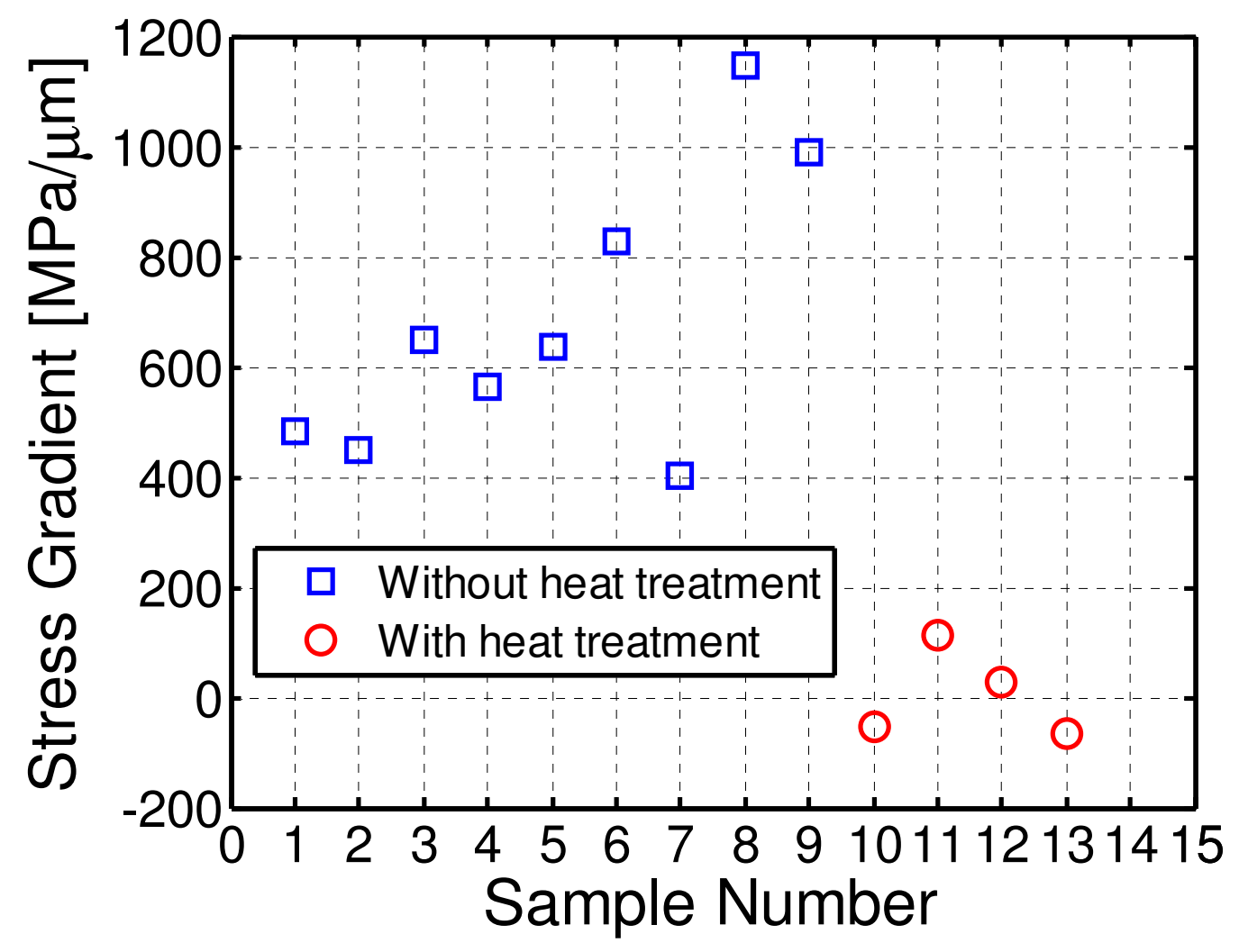

(a)

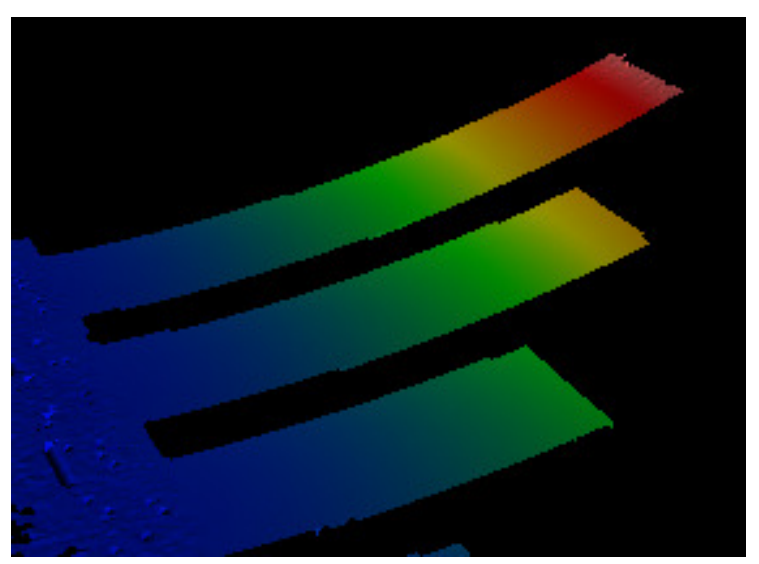

(b)

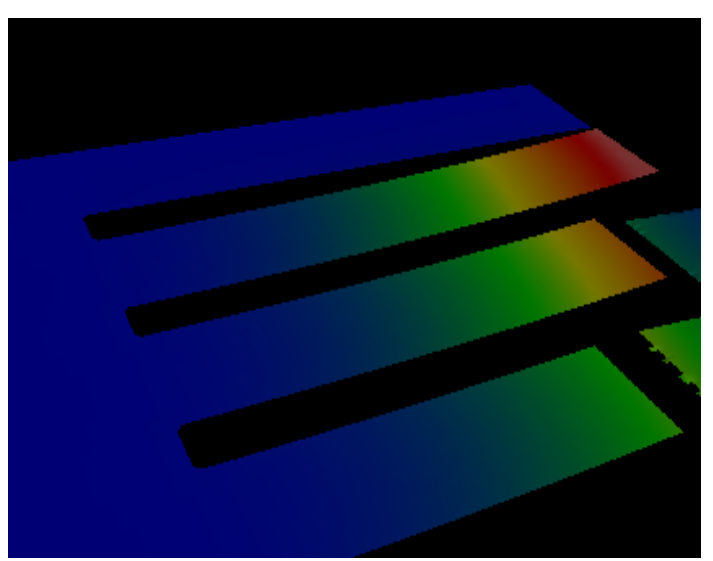

(c)

Figure 4. (a) Calculated stress gradient for different cantilever beams without heat treatment (blue squares marks) and with heat treatment (red circular marks). The lower part of the figure shows interferometric images of the beams without (b) and with (c) heat treatment. 


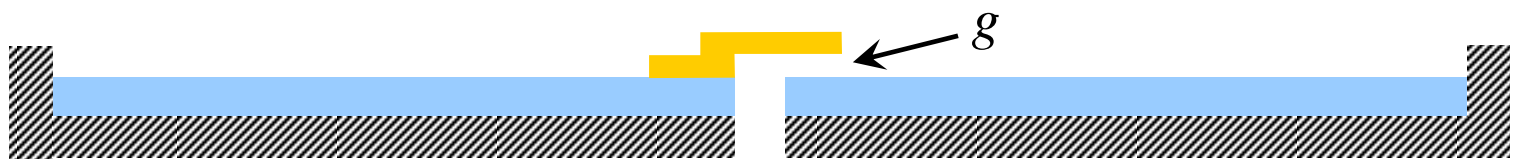

(a)

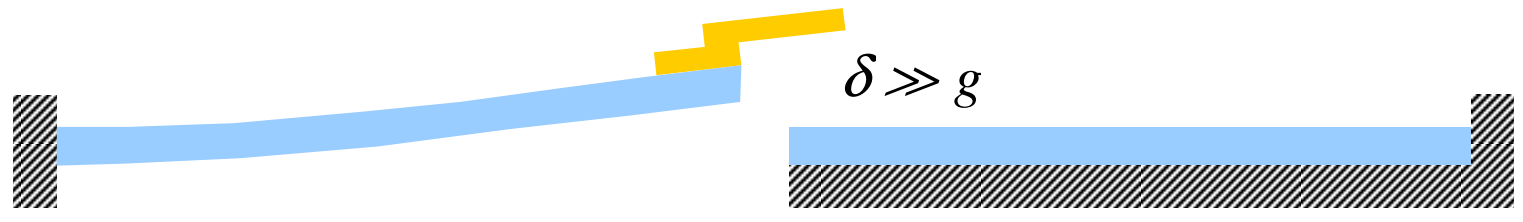

(b)

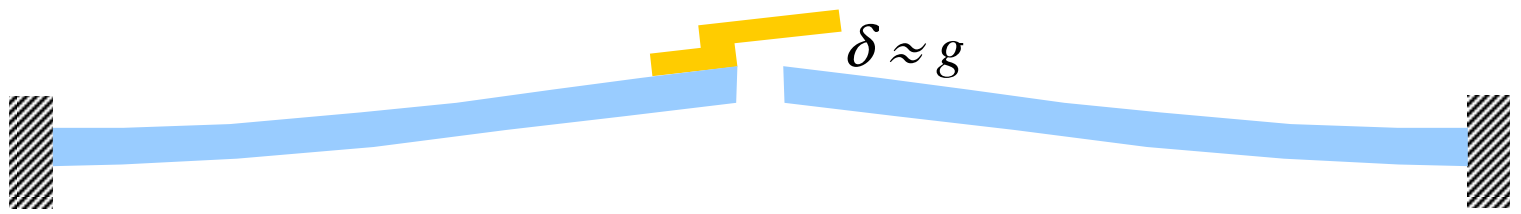

(c)

Figure 5. Schematic representation of stress gradient compensation enabled by the dual beam mechanism. (a) shows an unreleased switch with air-gap, $g$; (b) represents what would happen if just one beam is released and (c) shows what occurs when both beams are released. In this last case the gap size is preserved. The same is valid for when the switch structure is exposed to temperature variations. 

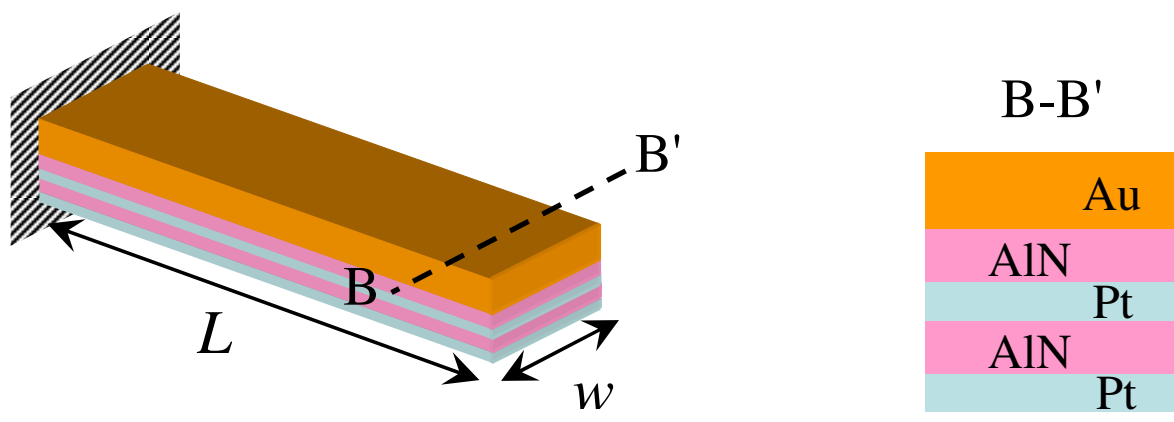

(a)

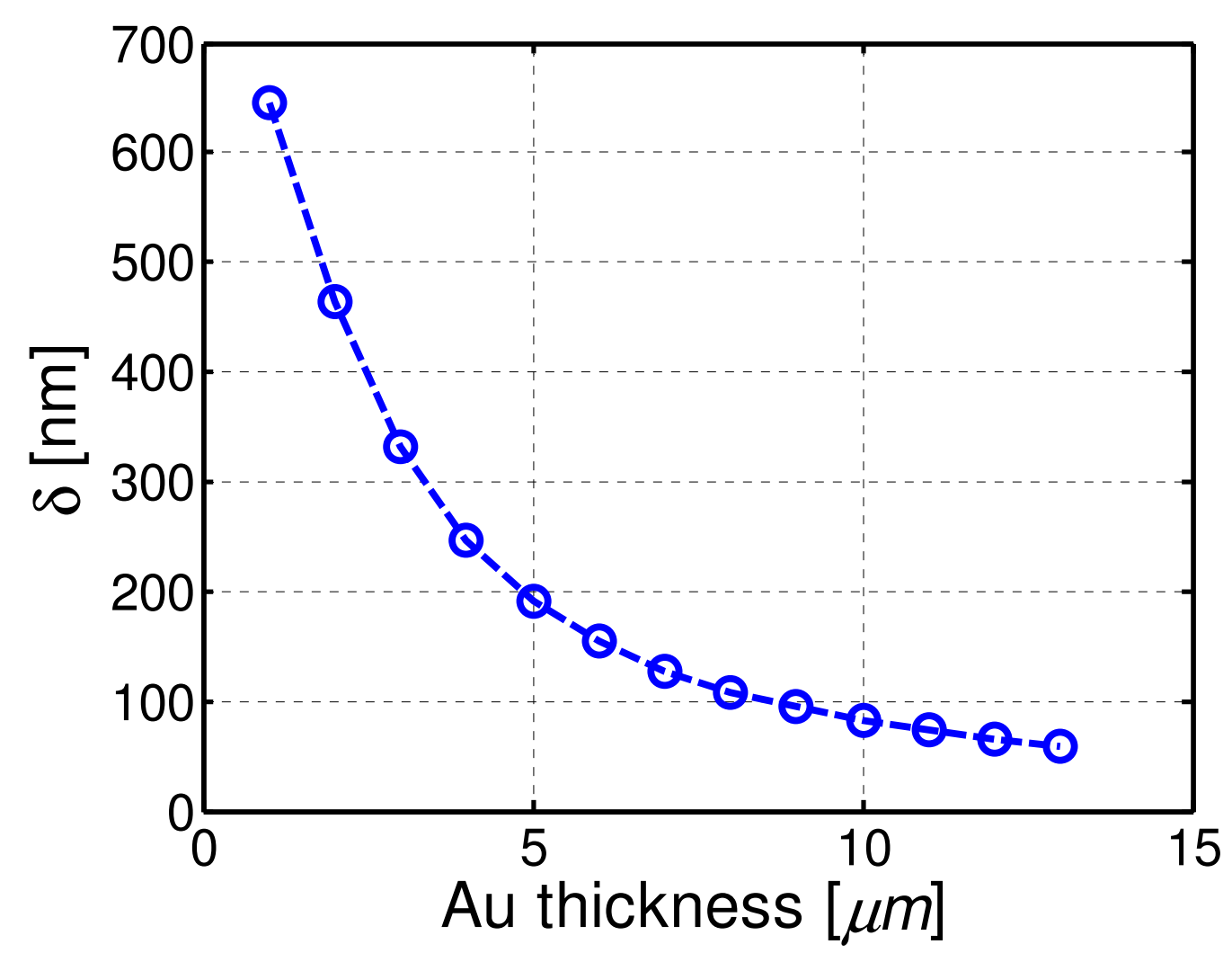

(b)

Figure 6. (a) Schematic view of piezoelectric unimorph actuator. (b) Beam edge deflection as function of $\mathrm{Au}$ thickness. The beam has a length, $L=200 \mu \mathrm{m}$, width, $w=200 \mu \mathrm{m}$, the AIN thickness is $t_{A l N}=1 \mu \mathrm{m}$, the Pt thickness is $t_{P t}=200 \mathrm{~nm}$ and the applied voltage for actuation is $V=25$ volt . 


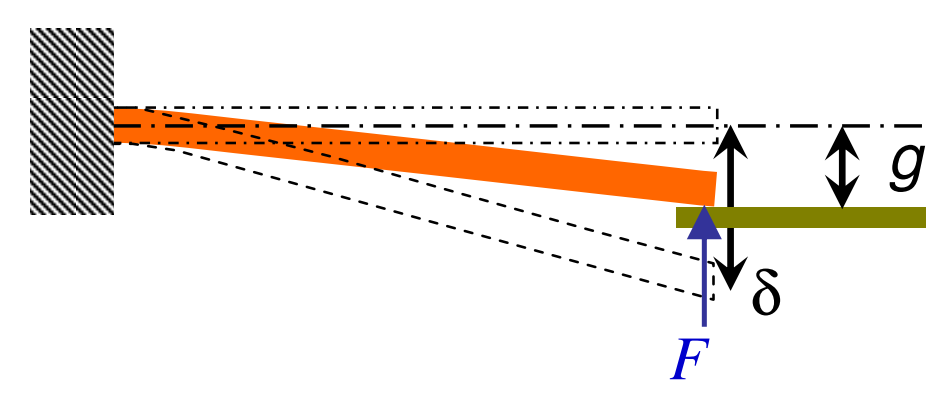

(a)

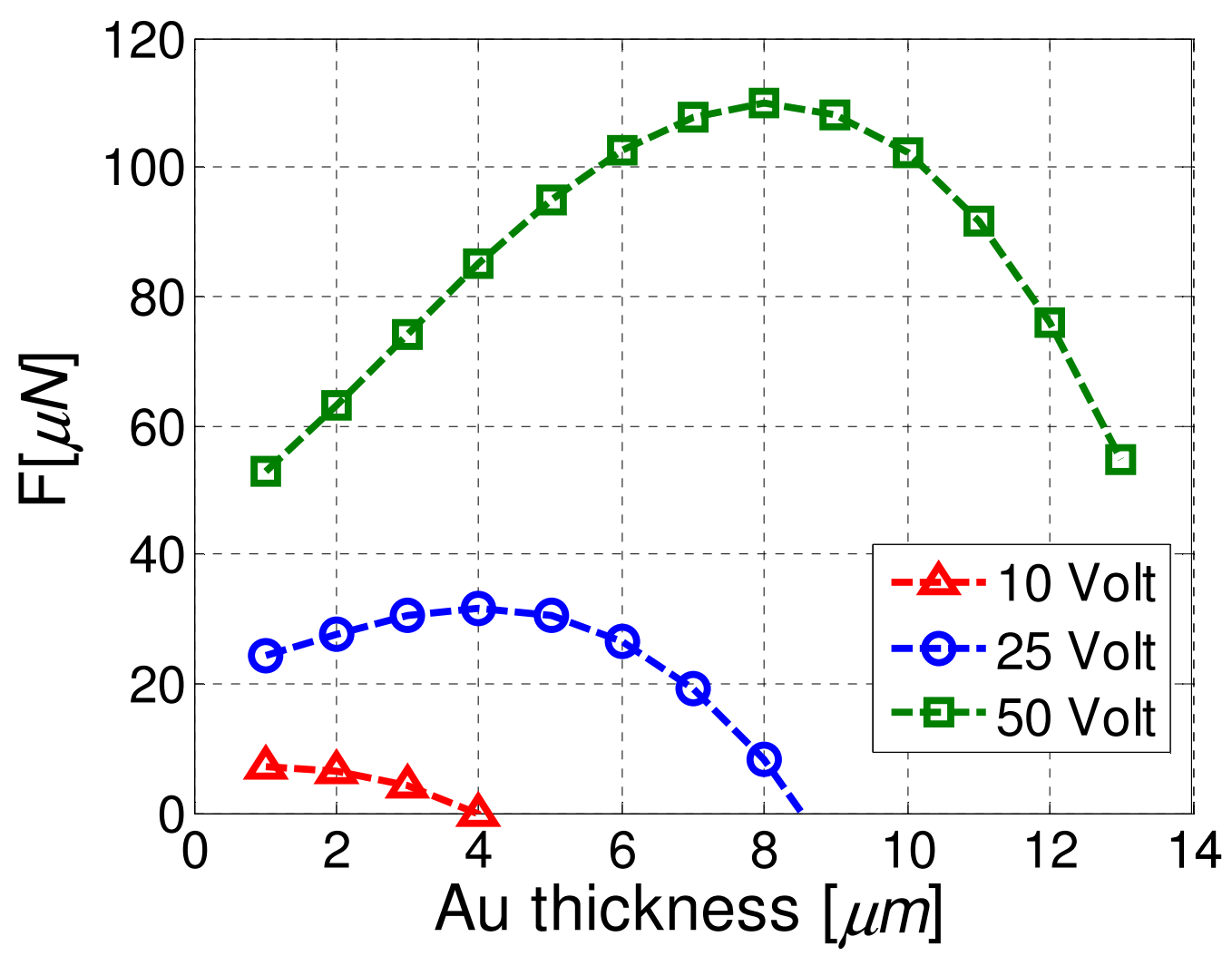

(b)

Figure 7. (a) Side view of piezoelectric unimorph actuator schematically illustrating the method used to calculate contact force. (b) The simulated contact force for the following beam geometry $L=200 \mu \mathrm{m}, w=200 \mu \mathrm{m}, t_{A l N}=1 \mu \mathrm{m}, t_{P t}=200 \mathrm{~nm}, g=200 \mathrm{~nm}$ as a function of Au thickness and different values of applied voltage. 


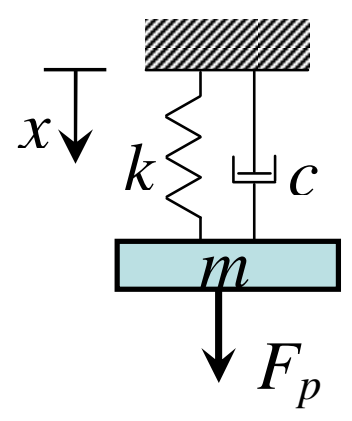

(a)

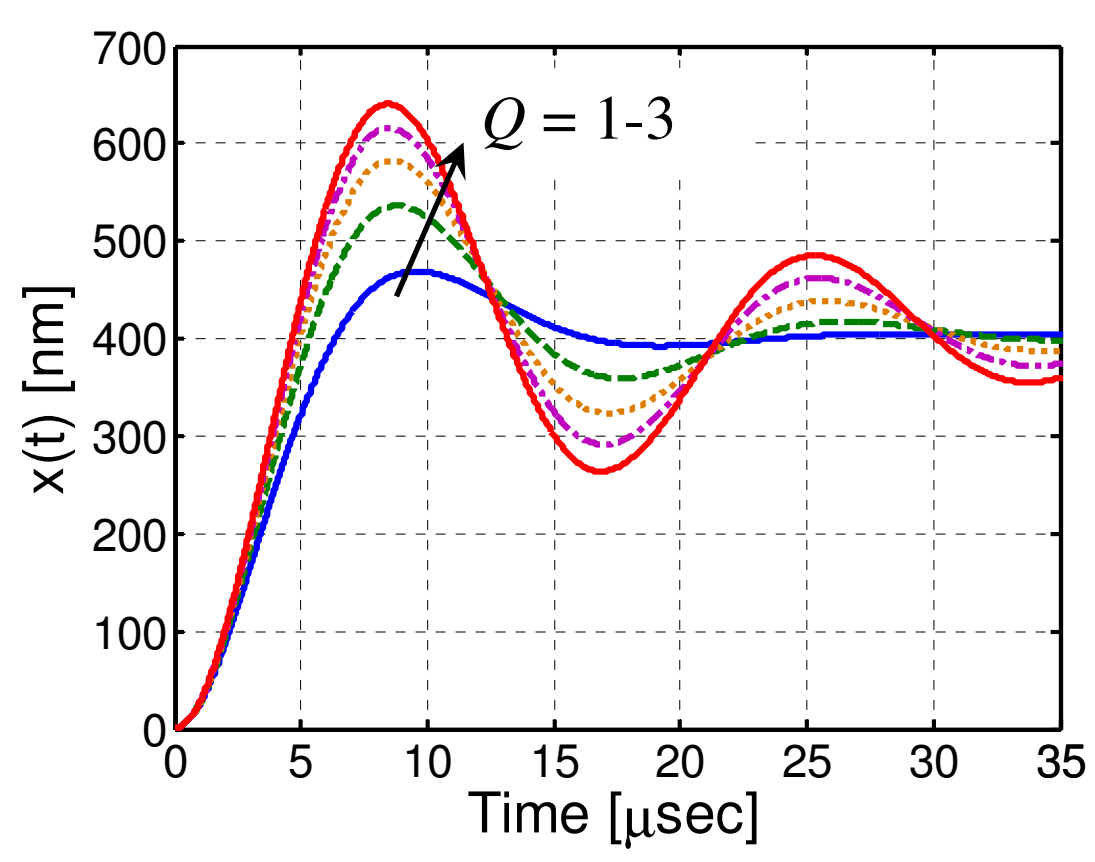

(b)

Figure 8. (a) Schematic representation of the second-order system used to model the switch dynamic response. Here, $k$ represents the beam stiffness, $c$ the coefficient of damping in the system, $m$ mass of the system and $F_{p}$ the equivalent driving force due to piezoelectric actuation of the beam. (b) Dynamic response of the equivalent second-order system for different values of quality factor (Q). A beam dimension of $L \times w=200 \mu \mathrm{m} \times 200 \mu \mathrm{m}, t_{A l N}=1 \mu \mathrm{m}, t_{P t}=200 \mathrm{~nm}$ with $2.3 \mu \mathrm{m}$ Au thickness was assumed. An actuation voltage of $V=22$ volt was used. 


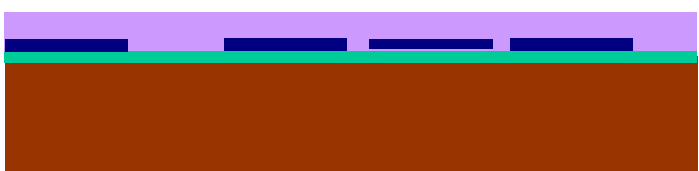

(a)

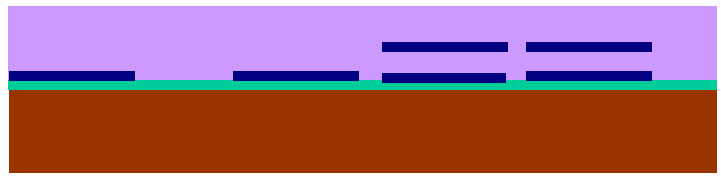

(b)

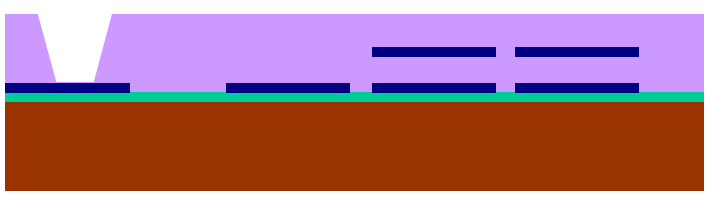

(c)

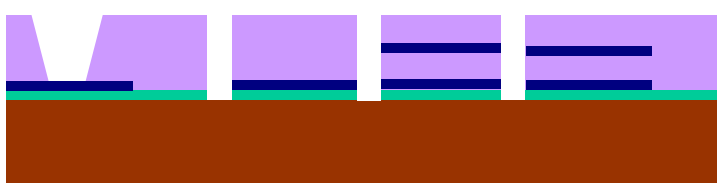

(d)

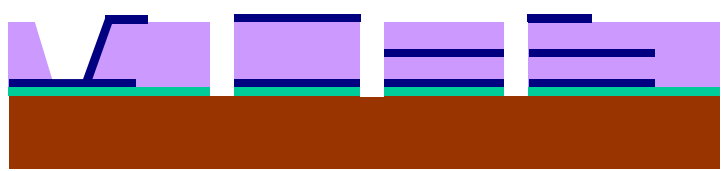

(e)

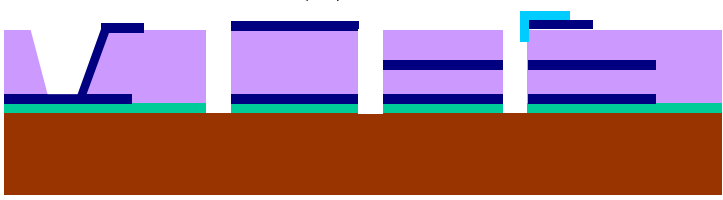

(f)

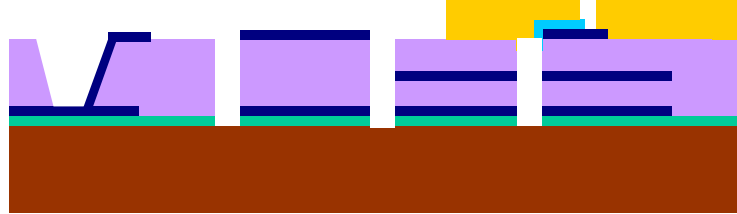

Resonator

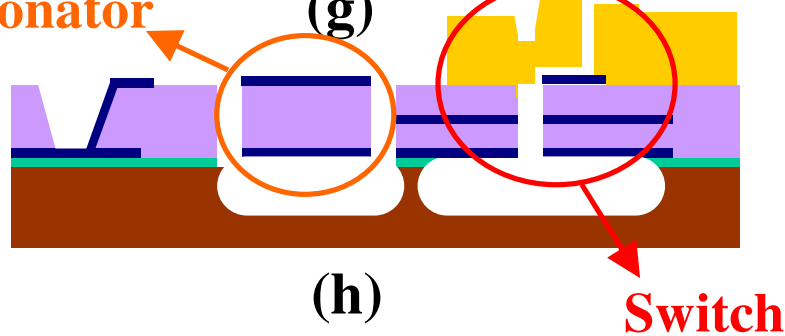

(h)
Switch

$\square$ Si LSN Pt AIN Si Gold

Figure 9. Process flow of the dual-beam switch fabricated with contour-mode resonators. (a) First AlN layer on top of Pt and LSN. (b) Second AlN layer on top of middle Pt. (c) Opening of via to bottom and middle Pt. (d) AlN Etch. (e) Top Pt deposition. (f) Si sacrificial layer. (g) Gold Electroplating. (h) $\mathrm{XeF}_{2}$ Release of structures. 


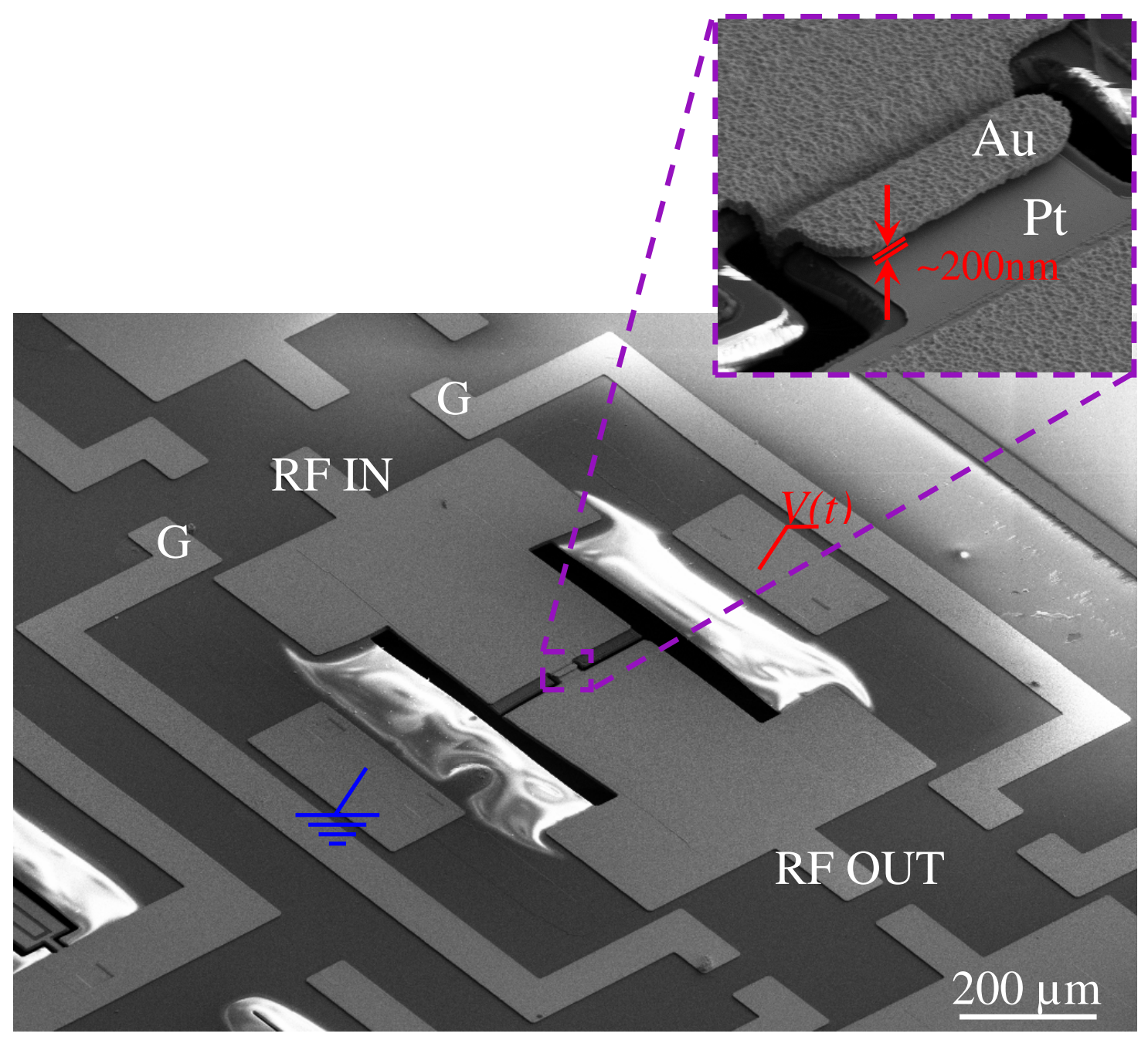

Figure 10. SEM of the fabricated AlN switch with a zoomed in view of the nano-gap and $\mathrm{Au} / \mathrm{Pt}$ contact region. The nano-gap is realized by using evaporated amorphous silicon as sacrificial layer. The sacrificial layer is removed by using $\mathrm{XeF}_{2}$ vapor phase release. The nano-gap definition is key in enabling switches with large forces and good RF isolation. 


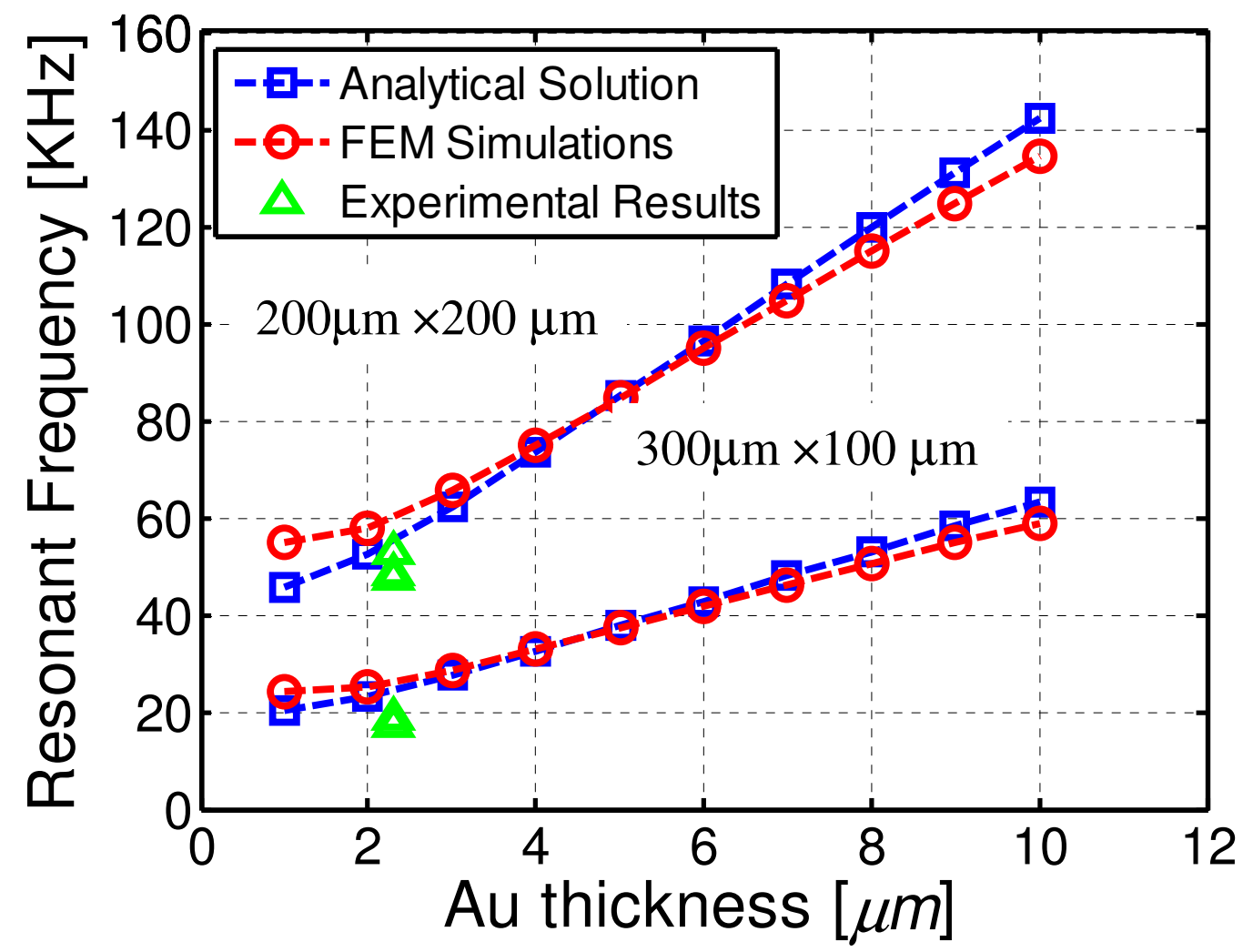

Figure 11. Comparison between measured, simulated and analytically calculated resonant frequencies of several $200 \mu m \times 200 \mu m$ and $300 \mu m \times 100 \mu m$ actuators with Au thickness $t_{A u}=2.3 \mu \mathrm{m}$. Simulation results for different Au thicknesses are also provided to show how Au thickness can be employed to fine tune the device resonant frequency. 


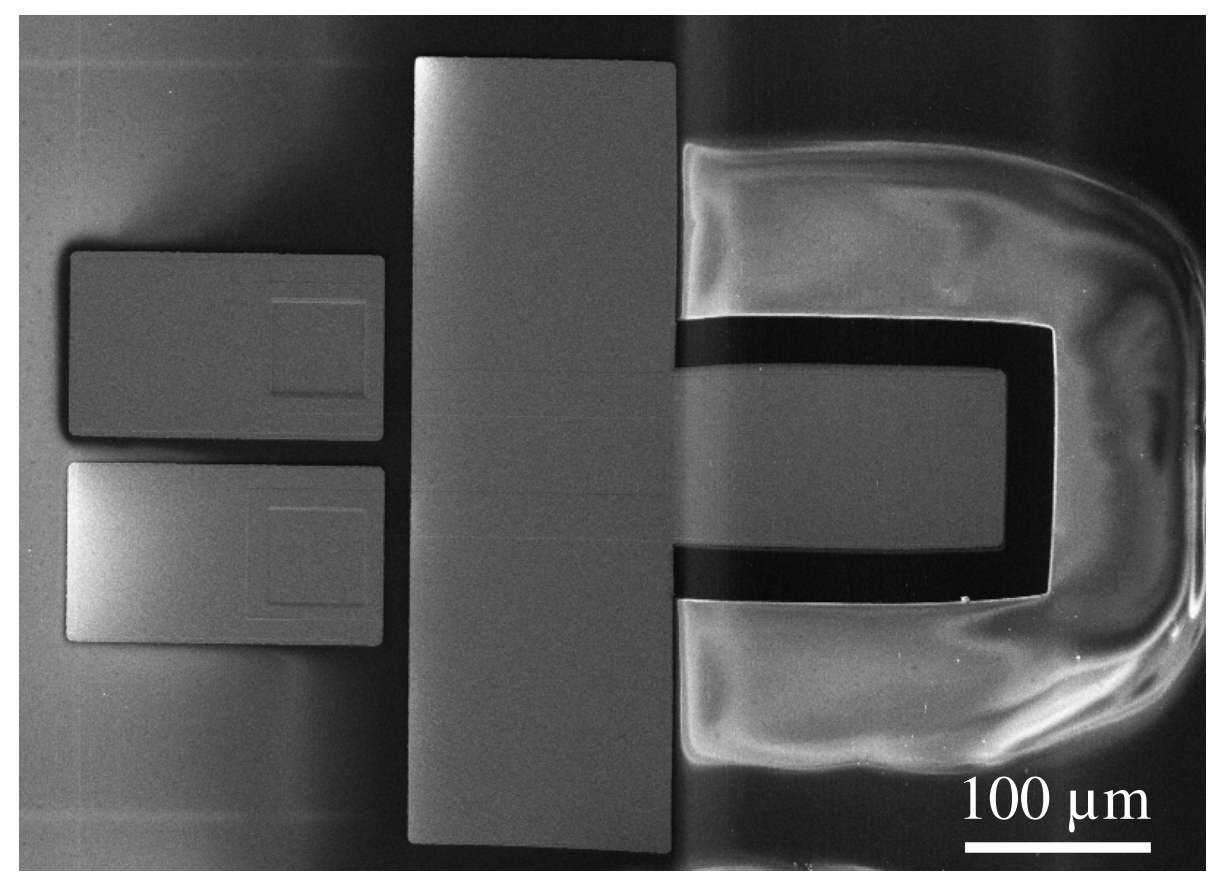

Figure 12. SEM of a fabricated piezoelectric actuator. The bright color around the trench demonstrates the isotropic etch of silicon around the structures by $\mathrm{XeF}_{2}$. To reduce the effect of the unwanted released area (underneath the anchor) on the structure stiffness, the trench width can be reduced in the area close to the anchor. In this case a thick and wide Au layer was used to stiffen the clamping location. 


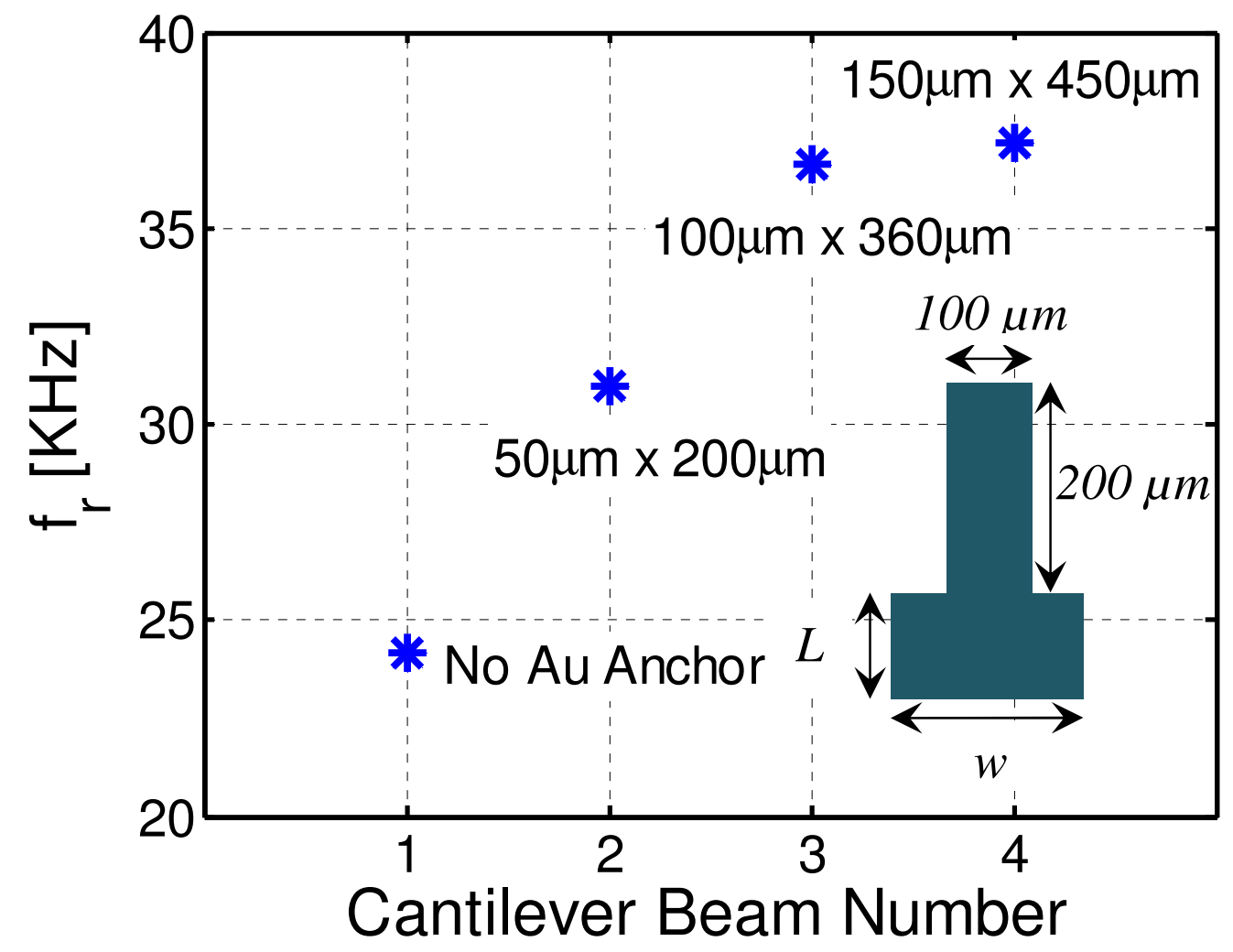

Figure 13. Measured resonant frequency of several $200 \mu m \times 100 \mu m$ for different Au anchor size. The inset represents the beam and anchor geometry. The beam size is fixed ( $200 \mu m \times 100 \mu m$ ) whereas width and length of the anchor are changed. In these test structures the resonant frequency is also affected strongly by the increasing in the effective beams length after the isotropic release of the structure in $\mathrm{XeF}_{2}$. 


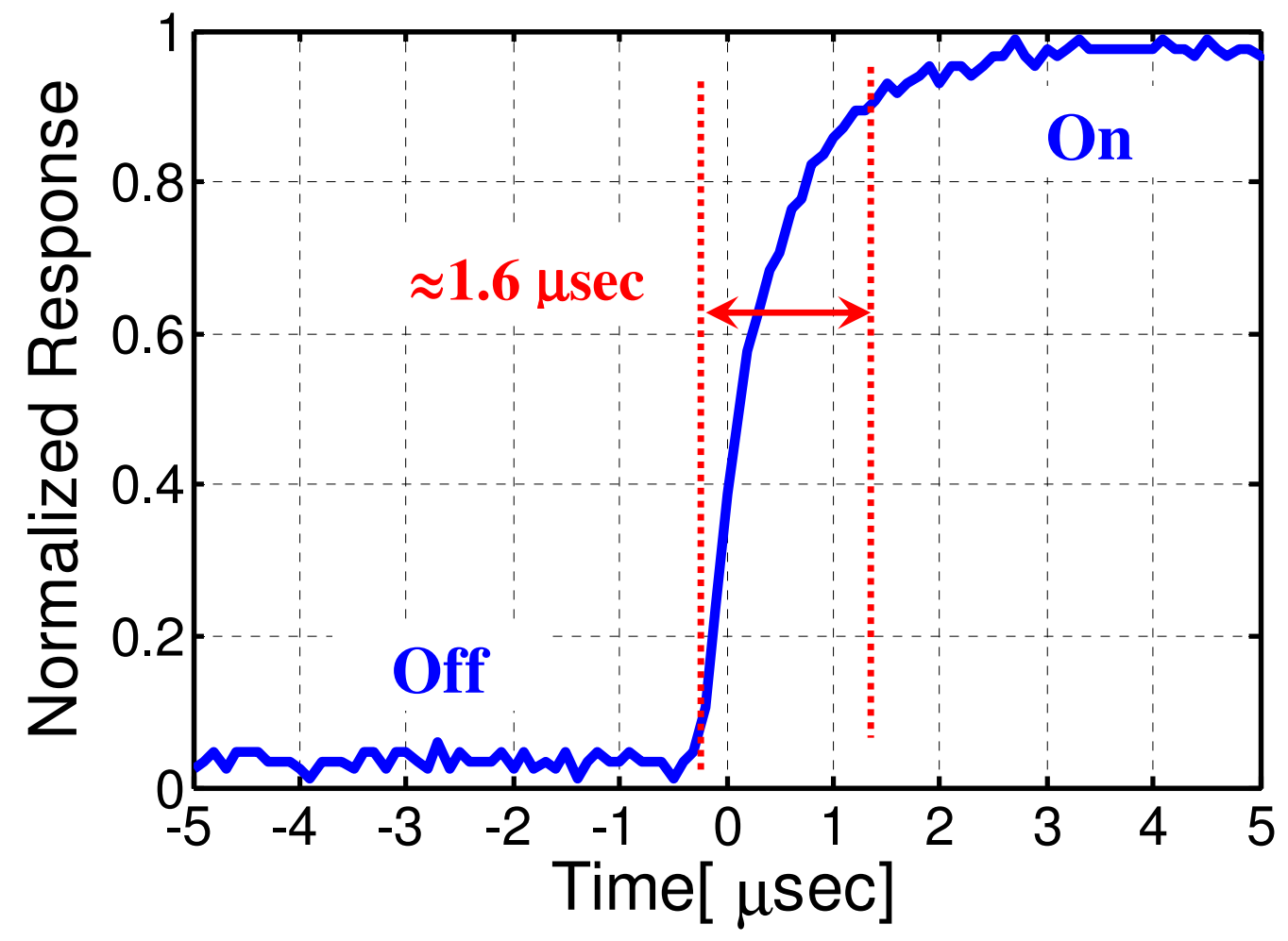

Figure 14. Response of the $200 \mu m \times 200 \mu m$ switch to a square waveform signal $( \pm 22 \mathrm{~V})$ at $40 \mathrm{~Hz}$. The square waveform was used to turn the switch on and off, while the change in a DC signal applied across the RF line was monitored to measure the occurrence of contact. 


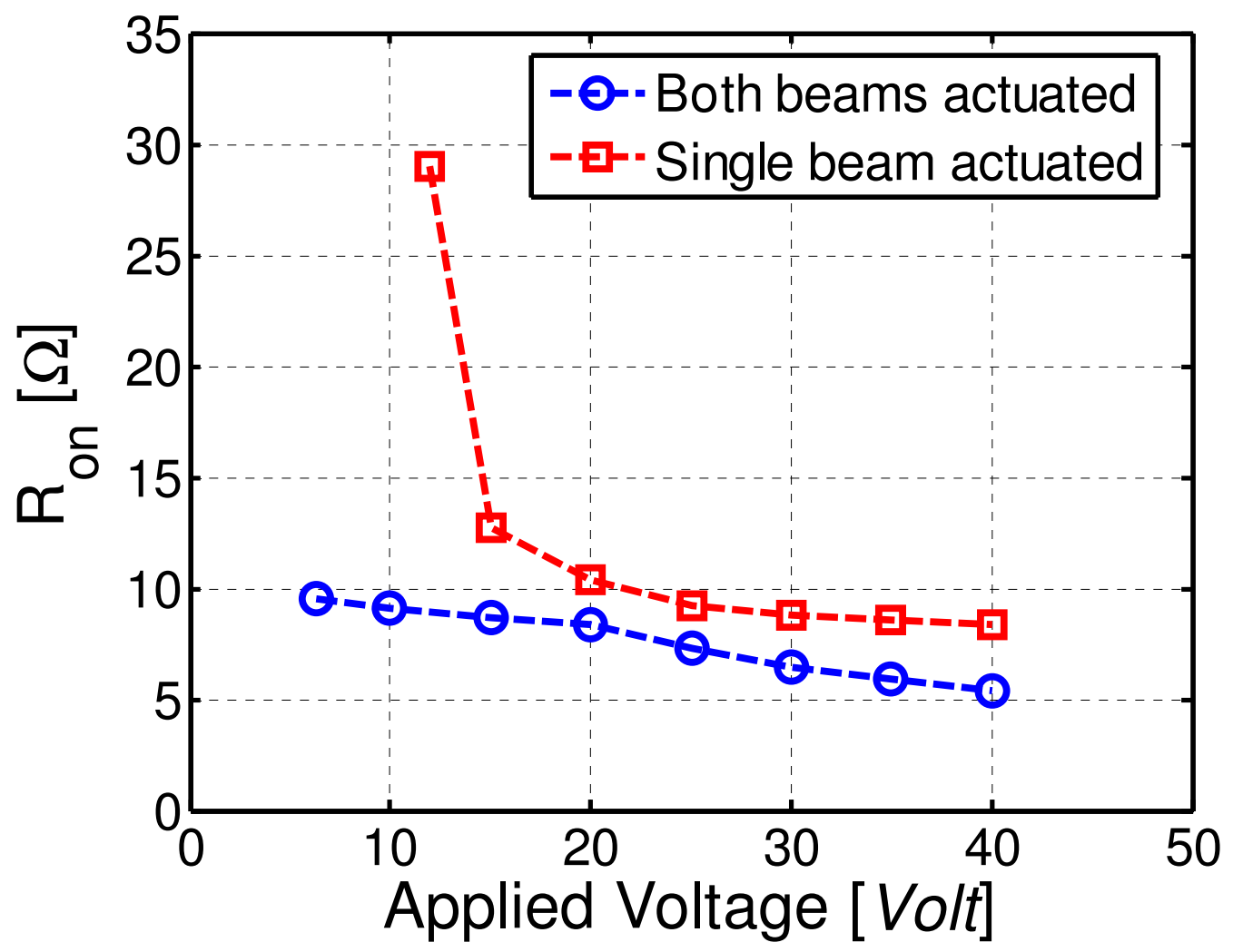

Figure 15. DC on resistance $\left(R_{o n}\right)$ measurements of a switch $(200 \mu m \times 200 \mu m)$ for which single and both beams were actuated. The dual beam actuation shows lower resistance for a given voltage. 


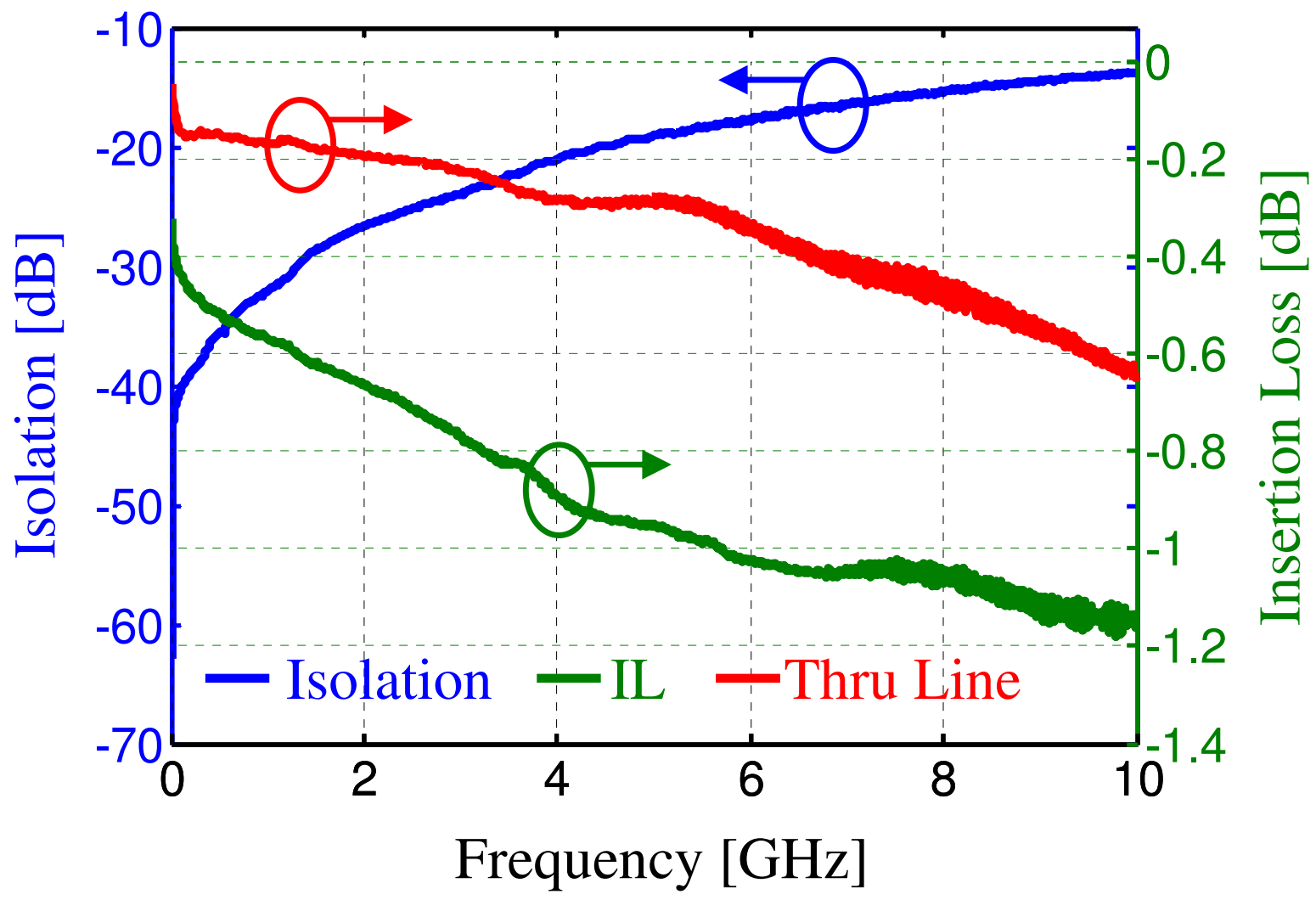

Figure 16. Measurement of isolation and insertion loss (IL) for a $200 \mu m \times 200 \mu m$ dual-beam AlN switch from $10 \mathrm{MHz}$ to $10 \mathrm{GHz}$. Switch IL is compared to the loss in a through line of comparable length. 


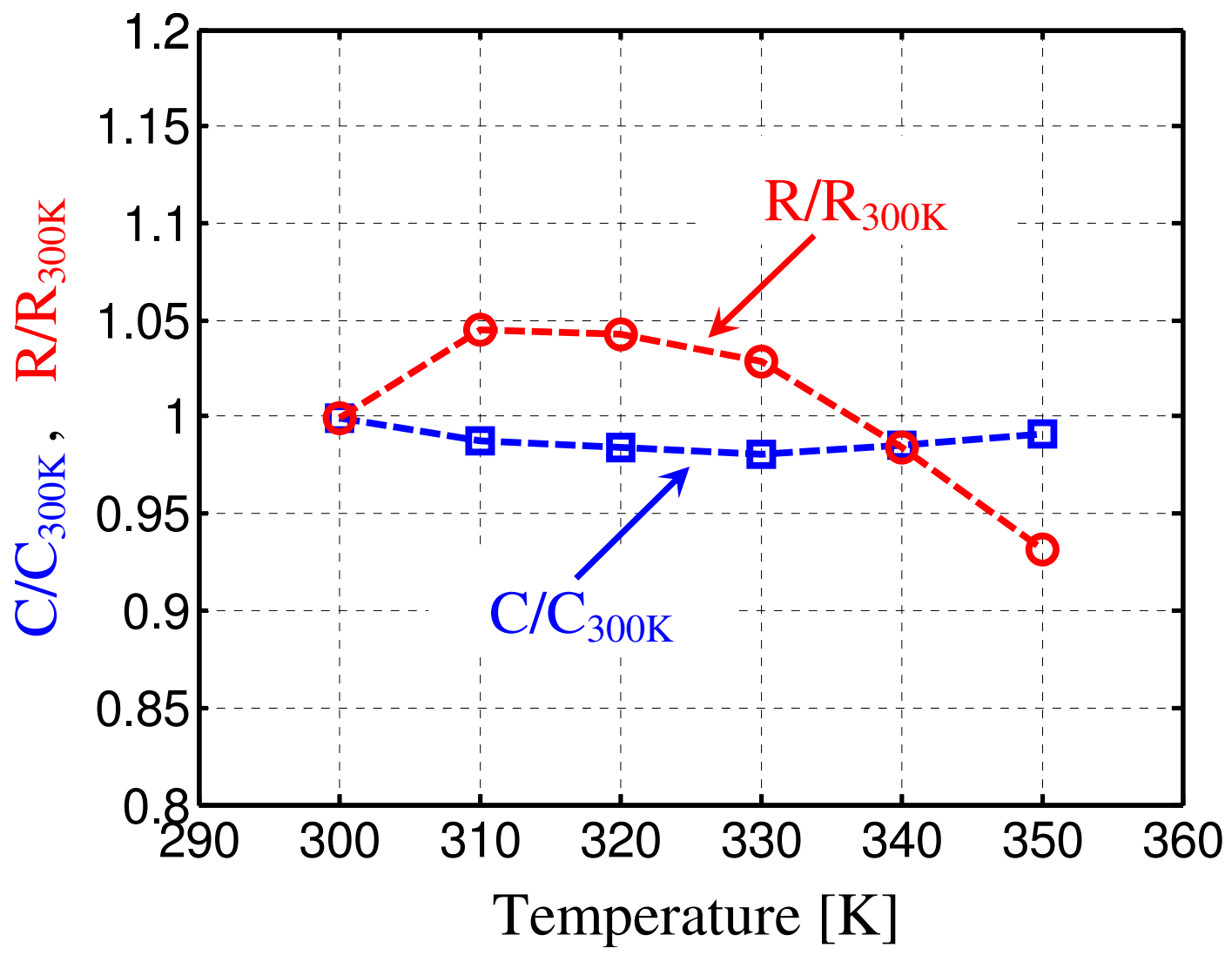

Figure 17. Normalized capacitance (at $2 \mathrm{GHz}$ ) and normalized on-resistance (at DC) of $300 \mu m \times 100 \mu m$ switch versus temperature. 


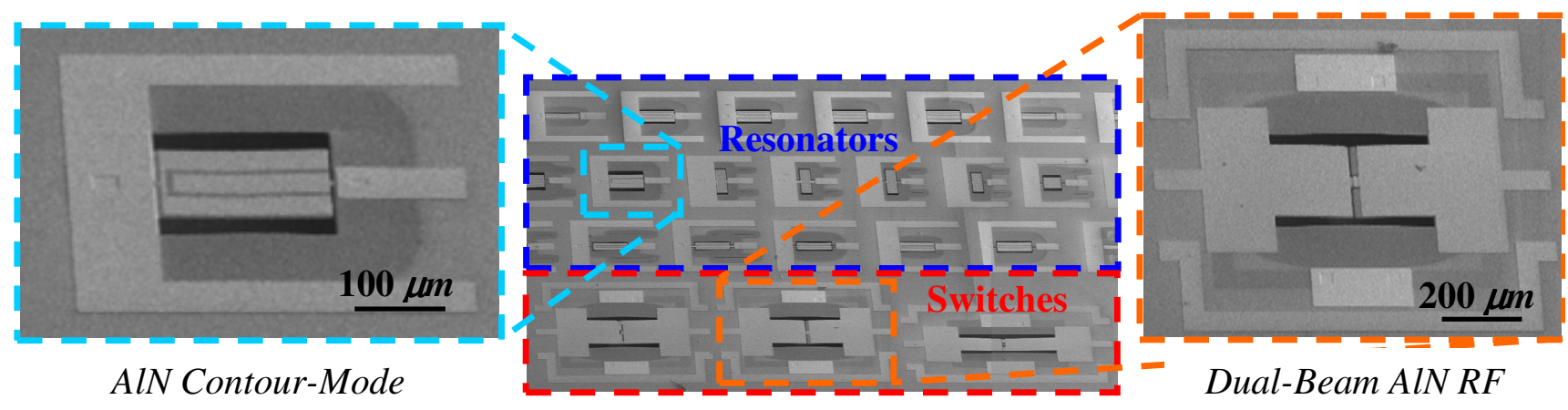

Figure 18. SEM showing dual-beam actuated AlN switches co-fabricated with AlN resonators on the same silicon substrate. 


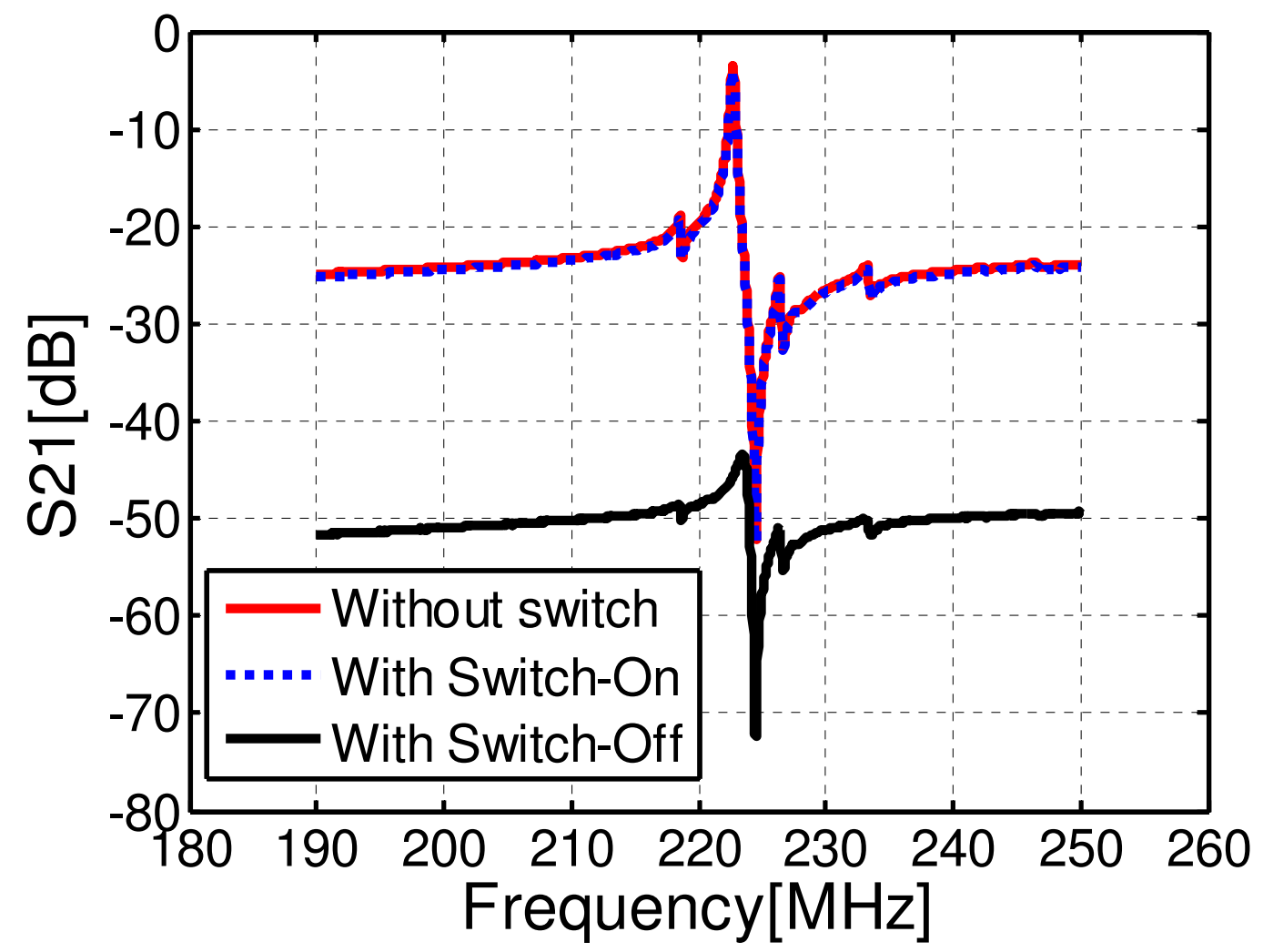

Figure 19. $\mathrm{S}_{21}$ plot (cascaded S-parameters) of a resonator monolithically integrated with the AlN switch presented in this work. The response of a resonator with the switch in both on and off states is compared to the response of the resonator without the switch. No significant changes in the resonator response were recorded. The resonator is effectively turned off by the switch. 


\section{References}

[1] G. M. Rebeiz, RF MEMS Theory, Design and Technology. Hoboken, New Jersey: John Wiley \& Sons, Inc., 2003.

[2] P. M. Zavracky, S. Majumder, and N. E. McGruer, "Micromechanical switches fabricated using nickel surface micromachining," J. of Microelectromechanical Systems, vol. 6, pp. 3-9, 1997.

[3] C. Bozler, R. Drangmeister, M. G. S. Duffy, J. Knecht, L. Kushner, R. Parr, S. Rabe, and L. Travis, "MEMS microswitch arrays for reconfigurable distributed microwave components," IEEE MTT-S Int. Microwave Symposium Digest, pp. 153-156, 2000.

[4] S. Duffy, C. Bozler, S. Rabe, J. Knecht, L. Travis, P. Wyatt, C. Keast, and M. Gouker, "MEMS microswitches for reconfigurable microwave circuitry," IEEE Microwave and Wireless Components Letters, vol. 11, pp. 106-108, 2001.

[5] S. Pranonsatit, A. S. Holmes, I. D. Robertson, and S. Lucyszyn, "Single-pole eight-throw RF MEMS rotary switch," J. of Microelectromechanical Systems, vol. 15, pp. 1735-1744, 2006.

[6] R. E. Mihailovich, M. Kim, J. B. Hacker, E. A. Sovero, J. Studer, J. A. Higgins, and J. E. DeNatale, "MEM relay for reconfigurable RF circuits," IEEE Microwave and Wireless Components Letters, vol. 11, pp. 53-55, 2001.

[7] D. Hyman, J. Lam, B. Warneke, A. Schmitz, T. Y. Hsu, J. Brown, J. Schaffner, A. Walston, R. Y. Loo, M. Mehregany, and J. Lee, "Surface-micromachined RF MEMs switches on GaAs substrates," Int. J. of Rf and Microwave Computer-Aided Engineering, vol. 9, pp. 348-361, 1999.

[8] J. B. Muldavin and G. M. Rebeiz, "All-metal high-isolation series and series/shunt MEMS switches," IEEE Microwave and Wireless Components Letters, vol. 11, pp. 373375, 2001.

[9] H. C. Lee, J. H. Park, J. Y. Park, H. J. Nam, and J. U. Bu, "Design, fabrication and RF performances of two different types of piezoelectrically actuated Ohmic MEMS switches," J. of Micromechanics and Microengineering, vol. 15, pp. 2098-2104, 2005.

[10] J. H. Park, H. C. Lee, Y. H. Park, Y. D. Kim, C. H. Ji, J. Bu, and H. J. Nam, "A fully wafer-level packaged RF MEMS switch with low actuation voltage using a piezoelectric actuator," J. of Micromechanics and Microengineering, vol. 16, pp. 2281-2286, 2006.

[11] S. J. Gross, S. Tadigadapa, T. N. Jackson, S. Trolier-McKinstry, and Q. Q. Zhang, "Leadzirconate-titanate-based piezoelectric micromachined switch," Appl. Phys. Lett., vol. 83, pp. 174-176, 2003.

[12] R. G. Polcawich, J. S. Pulskamp, D. Judy, P. Ranade, S. Trolier-McKinstry, and M. Dubey, "Surface micromachined microelectromechancial ohmic series switch using thinfilm piezoelectric actuators," IEEE Transactions on Microwave Theory and Techniques, vol. 55, pp. 2642-2654, 2007.

[13] M. C. Ruan, J. Shen, and C. B. Wheeler, "Latching micromagnetic relays," J. of Microelectromechanical Systems, vol. 10, pp. 511-517, 2001.

[14] Y. H. Zhang, G. F. Ding, X. F. Shun, D. H. Gu, B. C. Cai, and Z. S. Lai, "Preparing of a high speed bistable electromagnetic RF MEMS switch," Sensors and Actuators aPhysical, vol. 134, pp. 532-537, 2007. 
[15] T. Campbell, "MEMS Switch Technology Approaches the "Ideal Switch"," Applied Microwave \& Wireless, vol. 13, pp. 100-107, 2001.

[16] R. D. Streeter, C. A. Hall, R. Wood, and R. Madadevan, "VHF high-power tunable RF bandpass filter using microelectromechanical (MEM) microrelays," Int. J. RF Microwave CAE, pp. 261-275, 2001.

[17] E. J. J. Kruglick and K. S. J. Pister, "Lateral MEMS microcontact considerations," J. of Microelectromechanical Systems, vol. 8, pp. 264-271, 1999.

[18] R. Wood, R. Mahadevan, V. Dhuler, B. Dudley, A. Cowen, E. Hill, and K. Markus, "MEMS microrelays," Mechatronics, vol. 8, pp. 535-547, 1998.

[19] G. Piazza, P. J. Stephanou, and A. P. Pisano, "Single-chip multiple-frequency ALN MEMS filters based on contour-mode piezoelectric resonators," $J$. of Microelectromechanical Systems, vol. 16, pp. 319-328, 2007.

[20] G. Piazza, P. J. Stephanou, and A. P. Pisano, "Piezoelectric aluminum nitride vibrating contour-mode MEMS resonators," J. of Microelectromechanical Systems, vol. 15, pp. 1406-1418, 2006.

[21] R. Ruby, P. Bradley, J. L. III, Y. Oshmyansky, and D. Figueredo, "Ultra-miniature high$\mathrm{Q}$ filters and duplexers using FBAR technology " Solid-State Circuits Conference Digest of Technical Papers. ISSCC. 2001 IEEE International, pp. 120-121, 438, 2001.

[22] G. Piazza, P. J. Stephanou, and A. P. Pisano, "One and two port piezoelectric higher order contour-mode MEMS resonators for mechanical signal processing," Solid-State Electronics, vol. 51, pp. 1596-1608, 2007.

[23] N. Sinha, R. Mahameed, C. Zuo, M. B. Pisani, C. R. Perez, and G. Piazza, "Dual-Beam Actuation of Piezoelectric AlN RF MEMS Switches Monolithically Integrated with AlN Contour-Mode Resonators," Hilton Head Workshop: A Solid-State Sensors, Actuators and Microsystems Workshop., 2008.

[24] C. Zuo, N. Sinha, M. B. Pisani, C. R. Perez, R. Mahameed, and G. Piazza, "ChannelSelect RF MEMS Filters Based On Self-Coupled A1N Contour-Mode Piezoelectric Resonators " 2007 IEEE International Ultrasonics Symposium, 2007.

[25] J. G. Smits, S. I. Dalke, and T. K. Cooney, "The Constituent Equations of Piezoelectric Bimorphs," Sensors and Actuators a-Physical, vol. 28, pp. 41-61, 1991.

[26] D. L. DeVoe and A. P. Pisano, "Modeling and optimal design of piezoelectric cantilever microactuators," J. of Microelectromechanical Systems, vol. 6, pp. 266-270, 1997.

[27] E. Elka, D. Elata, and H. Abramovich, "The electromechanical response of multilayered piezoelectric structures," J. of Microelectromechanical Systems, vol. 13, pp. 332-341, 2004.

[28] T.-R. Hsu and N. Sun, "Residual Stresses/Strains Analysis of MEMS," Int. Conf. on Modeling and Simulation of Microsystems, Semiconductors, Sensors and Actuators, 1998

[29] L. A. Starman, J. A. Lott, M. S. Amer, W. D. Cowan, and J. D. Busbee, "Stress characterization of MEMS microbridges by micro-Raman spectroscopy," Sensors and Actuators a-Physical, vol. 104, pp. 107-116, 2003.

[30] S. Chen, T. V. Baughn, Z. J. Yao, and C. L. Goldsmith, "A new in situ residual stress measurement method for a MEMS thin fixed-fixed beam structure," $J$. of Microelectromechanical Systems, vol. 11, pp. 309-316, 2002. 
[31] T. Kawakubo, T. Nagano, M. Nishigaki, K. Abe, and K. Itaya, "RF-MEMS tunable capacitor with $3 \mathrm{~V}$ operation using folded beam piezoelectric bimorph actuator," J. of Microelectromechanical Systems, vol. 15, pp. 1759-1765, 2006.

[32] Q. M. Wang, X. H. Du, B. M. Xu, and L. E. Cross, "Electromechanical coupling and output efficiency of piezoelectric bending actuators," IEEE Transactions on Ultrasonics Ferroelectrics and Frequency Control, vol. 46, pp. 638-646, 1999.

[33] I. L. Guy, S. Muensit, and E. M. Goldys, "Extensional piezoelectric coefficients of gallium nitride and aluminum nitride," Applied Physics Letters, vol. 75, pp. 4133-4135, 1999.

[34] C. Zuo, N. Sinha, J. V. d. Spiegel, and G. Piazza, "Multi-Frequency Pierce Oscillators Based On Piezoelectric AlN Contour-Mode MEMS Resonators," 2008 IEEE International Frequency Control Symposium, May 2008.

[35] L. E. Mcneil, M. Grimsditch, and R. H. French, "Vibrational Spectroscopy of Aluminum Nitride," Journal of the American Ceramic Society, vol. 76, pp. 1132-1136, 1993.

[36] C. Deger, E. Born, H. Angerer, O. Ambacher, M. Stutzmann, J. Hornsteiner, E. Riha, and G. Fischerauer, "Sound velocity of AlxGa1-xN thin films obtained by surface acousticwave measurements," Applied Physics Letters, vol. 72, pp. 2400-2402, 1998. 